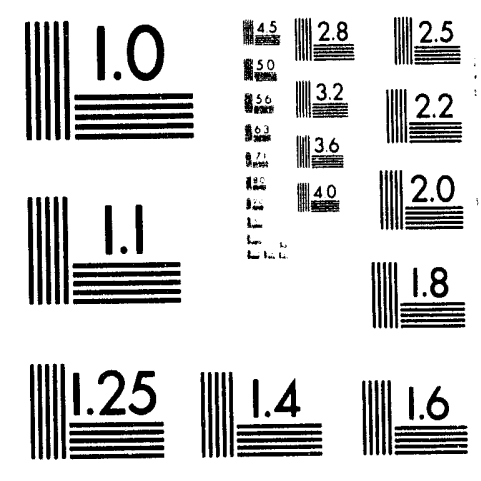



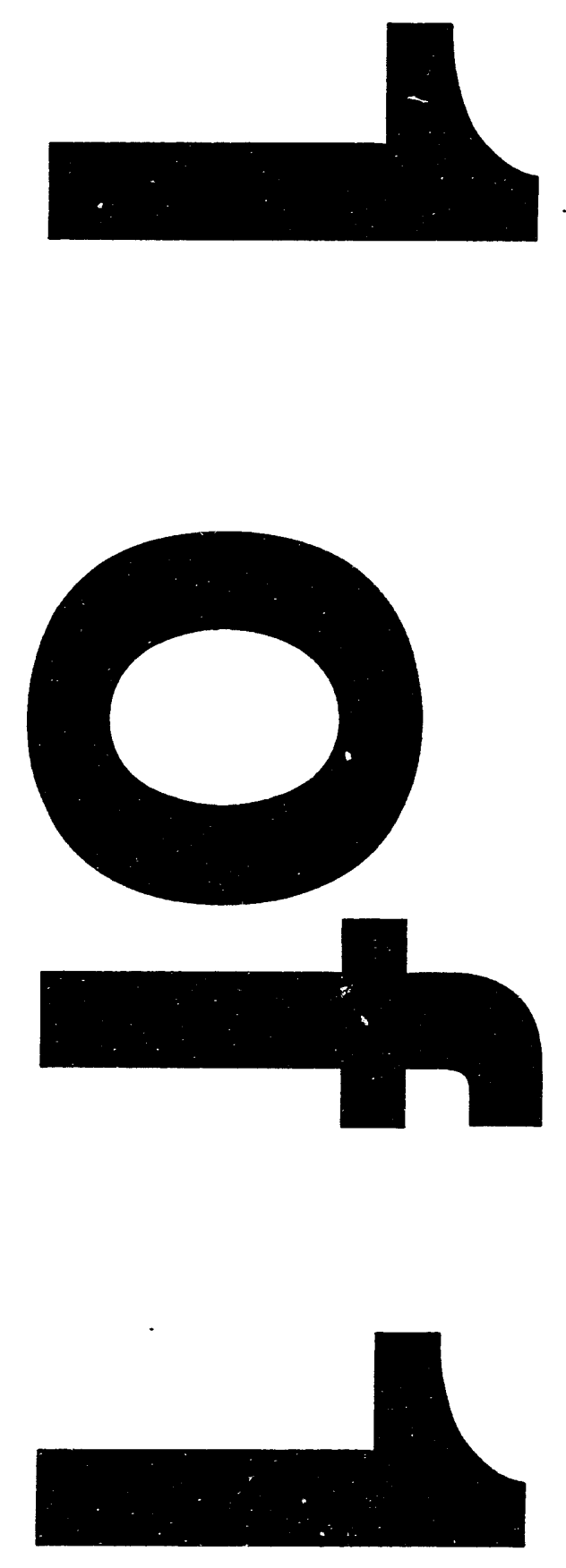
Engineering Technology Division

\title{
CREEP-FATIGUE CRITERIA AND INELASTIC BEHAVIOR OF MODIFIED 9CR-1MO STEEL AT ELEVATED TEMPERATURES
}

\section{FINAL REPORT}

\author{
M. B. Ruggles \\ Oak Ridge National Laboratory \\ Oak Ridge, Tennessee 37831-8051 \\ U.S.A. \\ T. Ogata \\ Central Research Institute of Electric Power Industry \\ Komae Research Laboratory \\ Tokyo 201, Japan
}

Date Published - February 1994

\author{
Prepared for the \\ Electric Power Research Institute
}

[Research Project 3030-10 (DOE-ERD-86-5860)]

Prepared by the

OAK RIDGE NATIONAL LABORATORY

Oak Ridge, Tennessee 37831-6285

managed by

MARTIN MARIETTA ENERGY SYSTEMS, INC.

for the

U.S. DEPARTMENT OF ENERGY

under contract DE-AC05-OR21400 


\section{CONTENTS}

1. INTRODUCTION ........................................................................

2. MATERIAL AND EXPERIMENTAL ARRANGEMENTS ................. 1

3. EXPLORATORY AXIAL DEFORMATION TESTS - CRIEPI ....... 4

4. UNIFIED CONSTITUTIVE EQUATIONS FOR INELASTIC ANALYSIS OF MODIFIED 9Cr-1MO STEEL ............................... 6

4.1 BASIC MODEL RECOMMENDATIONS ……….................. 6

4.2 MATHEMATICAL FRAMEWORK OF THE MODEL ............. 7

4.3 MODEL FITTING PROCEDURE ....................................... 10

4.3.1 STRAIN RATE SENSITIVITY, TEMPERATURE DEPENDENCE AND FLOW SOFTENING BEHAVIOR .................................................... 10

4.3.2 KINEMATIC HARDENING BEHAVIOR ................. 13

4.3.3 OVERSTRESS-INELASTIC STRAIN RATE TEMPERATURE RELATIONSHIP .......................... 15

4.3.4 THERMAL RECOVERY TERM ............................... 16

4.4 SUMMARY OF THEMODEL ……………………………..... 16

5. AXIAL FATIGUE AND CREEP-FATIGUE TESTS ..................... 19

5.1 LOW CYCLE FATIGUE TESTS ........................................ 19

5.2 VARIABLE STRAIN RATE FATIGUE TESTS ................. 23

5.3 CREEP-FATIGUE TESTS ……………………………...... 25

6. CONSTANT STRESS CREEP TESTS …………………………..... 34

7. BIAXIAL FATIGUE AND CREEP-FATIGUE TESTS .................... 40

7.1 LOW CYCLE FATIGUE TESTS ........................................ 40

7.2 CREEP-FATIGUE TESTS ................................................. 47

8. CREEP-FATIGUE LIFE EVALUATION ………………............... 49

8.1 LIFE EVALUATION WITH EXISTING METHOD ............. 49

8.2 LIFE EVALUATION WITH A NEW METHOD …………..... 53

9. CONCLUDING REMARKS ………………………………….......... 55

ACKNOWLEDGEMENT …………………………………………………... 56

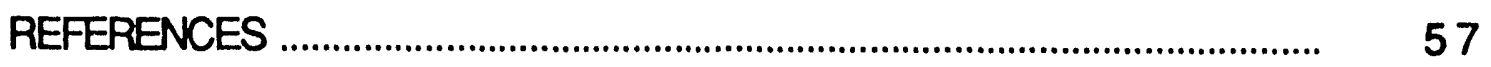




\section{INTRODUCTION}

The ever increasing demand for safety requires that stringent and conservative methodology be developed for design and analysis of reactor components. At present modified $9 \mathrm{Cr}-1 \mathrm{Mo}$ steel is a candidate material for construction of stean generators in fast breeder reactors. Therefore high-temperature material properties and extensive insight into deformation behavior and creep-fatigue life are required to develop design guidelines for use of modified $9 \mathrm{Cr}-1 \mathrm{Mo}$ steel in actual plant components. However, existing information on creep-fatigue and deformation response of modified $9 \mathrm{Cr}-1 \mathrm{Mo}$ steel is insufficient, and further experimental and modeling efforts are needed.

A joint effort between the Electric Power Research Institute (EPRI) in the United States and the Central Research Institute of Electric Power Industry (CRIEPI) in Japan was started in 1991 to investigate the inelastic behavior of and to develop creep-fatigue criteria for modified $9 \mathrm{Cr}-1 \mathrm{Mo}$ steel at elevated temperatures. The current program focuses on uniaxial and biaxial fatigue, creep, and creep-fatigue tests. Results of this effort are presented in the following sections. Section 2 introduces the test material and experimental arrangements. Uniaxial exploratory jeformation tests and unified constitutive equations for inelastic analysis of modified $9 \mathrm{Cr}-1 \mathrm{Mo}$ steel are presented in Sections 3 and 4 , respectively. Axial fatigue and creep-fatigue test results are discussed in Section 5. Section 6 is devoted to constant stress creep tests. Biaxial fatigue and creep-fatigue tests are described in Section 7. Progress in creepfatigue life evaluation is reported in Section 8.

\section{MATERIAL and EXPERIMENTAL ARRANGEMENTS}

The material tested was hot rolled modified $9 \mathrm{Cr}-1 \mathrm{Mo}$ steel (plate stock) with the following chemical composition (wt \%): $0.09 \mathrm{C} ; 0.24 \mathrm{Si}$; $0.44 \mathrm{Mn} ; 0.003 \mathrm{P} ; 0.001 \mathrm{~S} ; 0.04 \mathrm{Ni} ; 8.78 \mathrm{Cr} ; 0.94 \mathrm{Mo} ; 0.21 \mathrm{~V} ; 0.08 \mathrm{Nb}$; $0.013 \mathrm{Al}$. The $(1.0 \times 1.0 \times 0.05 \mathrm{~m})$ plates 'vere normalized at $1060^{\circ} \mathrm{C}$ for $90 \mathrm{~min}$, tempered at $760^{\circ} \mathrm{C}$ for $60 \mathrm{~min}$, and annealed at $740^{\circ} \mathrm{C}$ for 504 
min. Test specimens were cut from plate stock in the direction of rolling and tested in the "as machined" condition.

To establish basic material properties, tensile tests were carried out at CRIEPI at 20,100,200,300,400,500, and $550^{\circ} \mathrm{C}$ using the standard specimen shown in Fig. 2.1. Variations in proof stress and tensile strength with temperature are shown in Fig. 2.2. It is seen that proof stress and tensile strength decrease with increasing temperature. Presented in Fig. 2.3 are variations with temperature in elongation and reduction in area at the moment of rupture. It is seen that the modified $9 \mathrm{Cr}-1 \mathrm{Mo}$ steel exhibits considerable tensile ductility for the range of temperatures considered in this study.
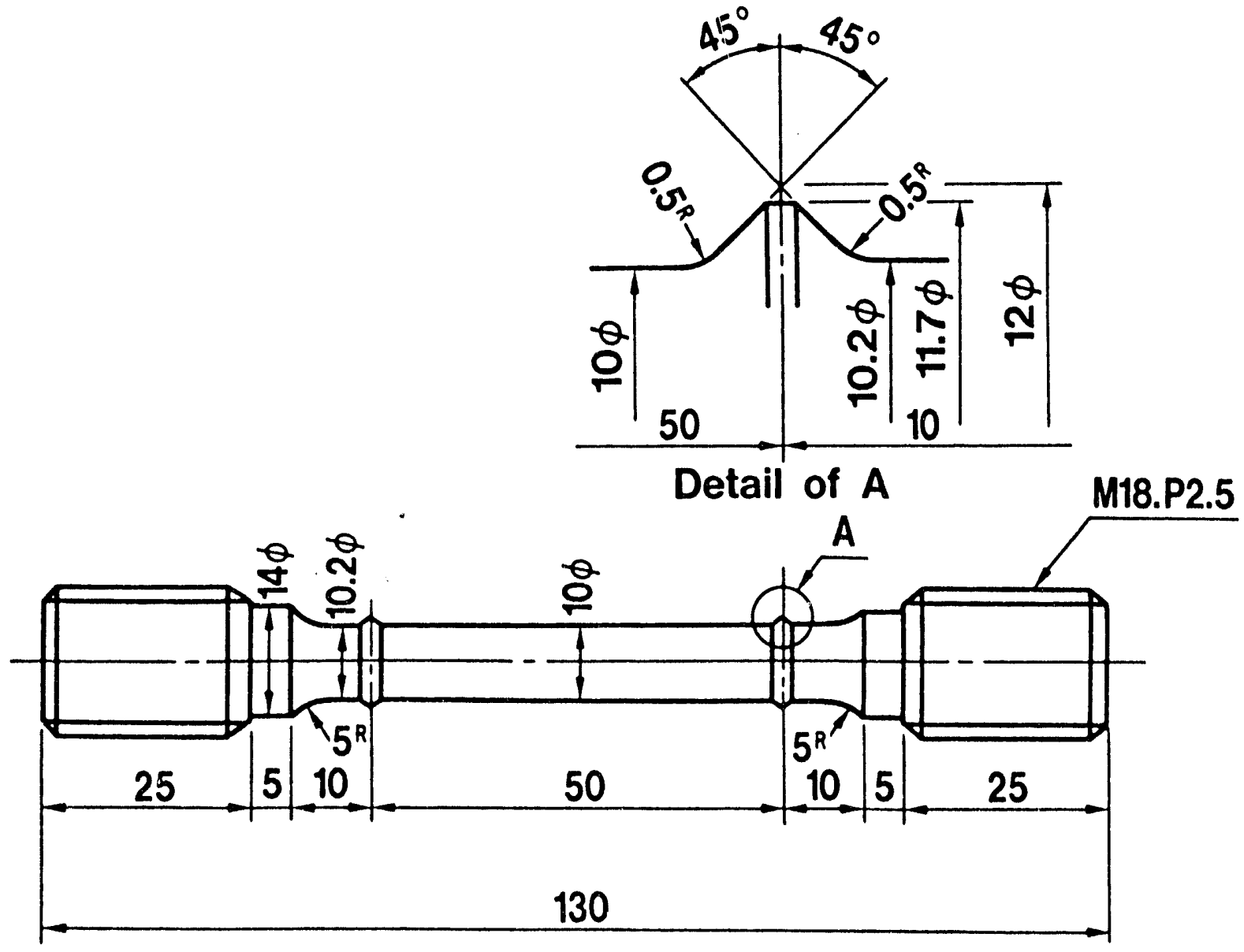

Fig. 2.1. CRIEPI Tensile Specimen 


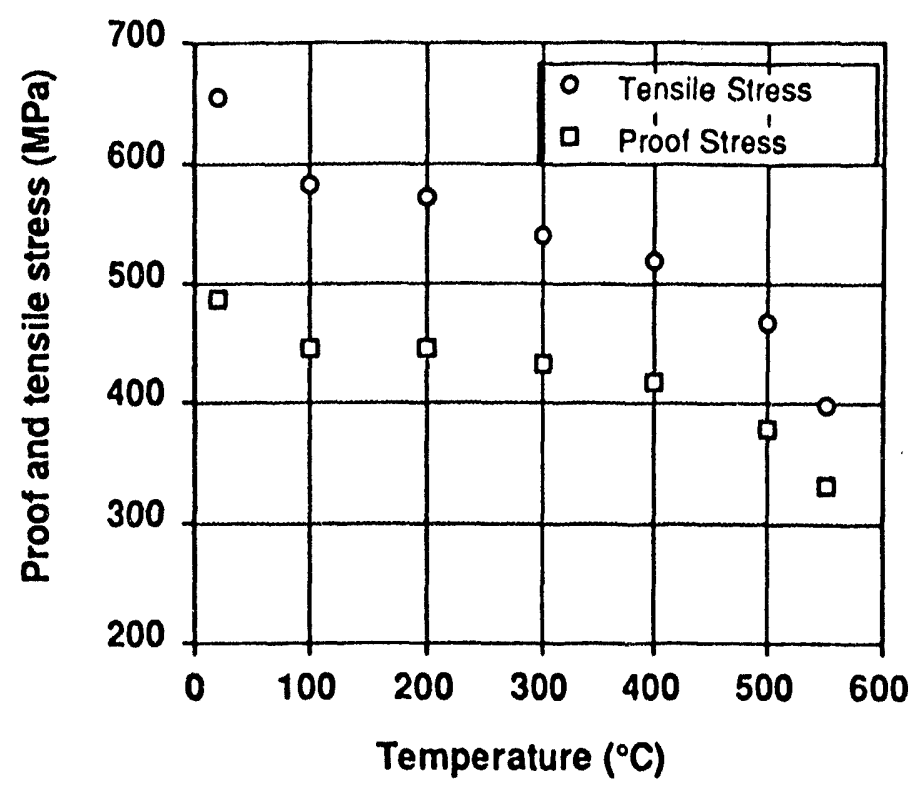

Fig. 2.2. Modified 9Cr-1Mo Steel. Variations in Proof Stress and Tensile Strength with Temperature.

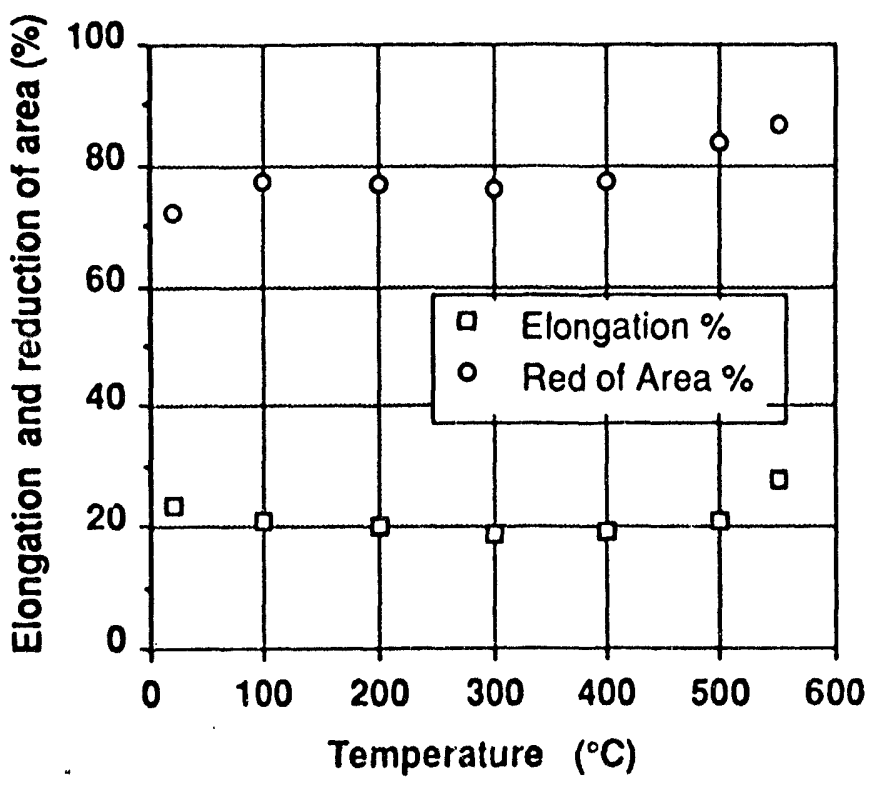

Fig. 2.3. Modified $9 \mathrm{Cr}-1$ Mo Steel. Variations in Elungation and Reduction in Area at Rupture with Temperature. 
All EPRI tests reported here were performed by the Oak Ridge National Laboratory (ORNL). All EPRI/ORNL tests were performed in an air environment. In all EPRI elevated temperature tests (except constant stress creep tests) a servocontrolled MTS axial-torsion mechanical testing machine together with an MTS digital TestStar Materials Testing Workstation was used for computerized testing and data acquisition. The load (engineering stress), displacement (engineering strain), number of cycles (where appropriate), and time were measured and recorded; the digitized test data were stored on hard and floppy disks. After the test the digitized data can be recalled for processing and interpretation. The entire history is available for analysis. Induction heating, MTS water cooled hydraulic collet grips, and an MTS high-temperature air-cooled axial extensometer of 25.4 $\mathrm{mm}$ gage length permitted axial elevated-temperature testing under load or displacement control. Ten thermocouples were placed on the gage section of the specimen. For the duration of the tests, the temperature in the gage section remained reasonably uniform, and stayed within $\pm 3^{\circ} \mathrm{C}$ of the nominal temperature. In very rare instances variations of $\pm 5^{\circ} \mathrm{C}$ were encountered.

\section{EXPLORATORY AXIAL DEFORMATION TESTS - CRIEPI}

Two uniaxial deformation tests were conducted at CRIEPI at $550^{\circ} \mathrm{C}$. Specimen TP1 was subjected to 5000 strain controlled cycles between $\varepsilon= \pm 0.25 \%$ followed by creep to rupture at a constant stress of $200 \mathrm{MPa}$. Time to rupture was 662 hours. Specimen TP2 was subjected to a $1000 \mathrm{~h}$ creep period at $200 \mathrm{MPa}$, followed by strain controlled cycling between $\varepsilon= \pm 0.25 \%$. Specimen TP2 failed after 10,500 cycles.

Creep curves for specimens TP1 and TP2 are presented in Fig. 3.1. The effect of prior cyclic loading on the creep response of specimen TP1 is clearly seen in Fig. 3.1. Steady-state creep is reached sooner and the steady state creep rate is considerably higher for specimen TP1 than for specimen TP2. It appears that prior cyclic loading accompanied by cyclic softening has reduced the creep 
resistance of specimen TP1. In addition, the creep rupture time for specimen TP1 was also considerably reduced.

Shown in Fig. 3.2 is the variation in maximum tensile stress with the number of cycles for both specimens. It is seen that maximum tensile stress values obtained for specimen TP2 are slightly lower than those obtained for TP1, which may be the effect of prior creep loading. However, fatigue life does not appear to be significantly affected by prior creep.

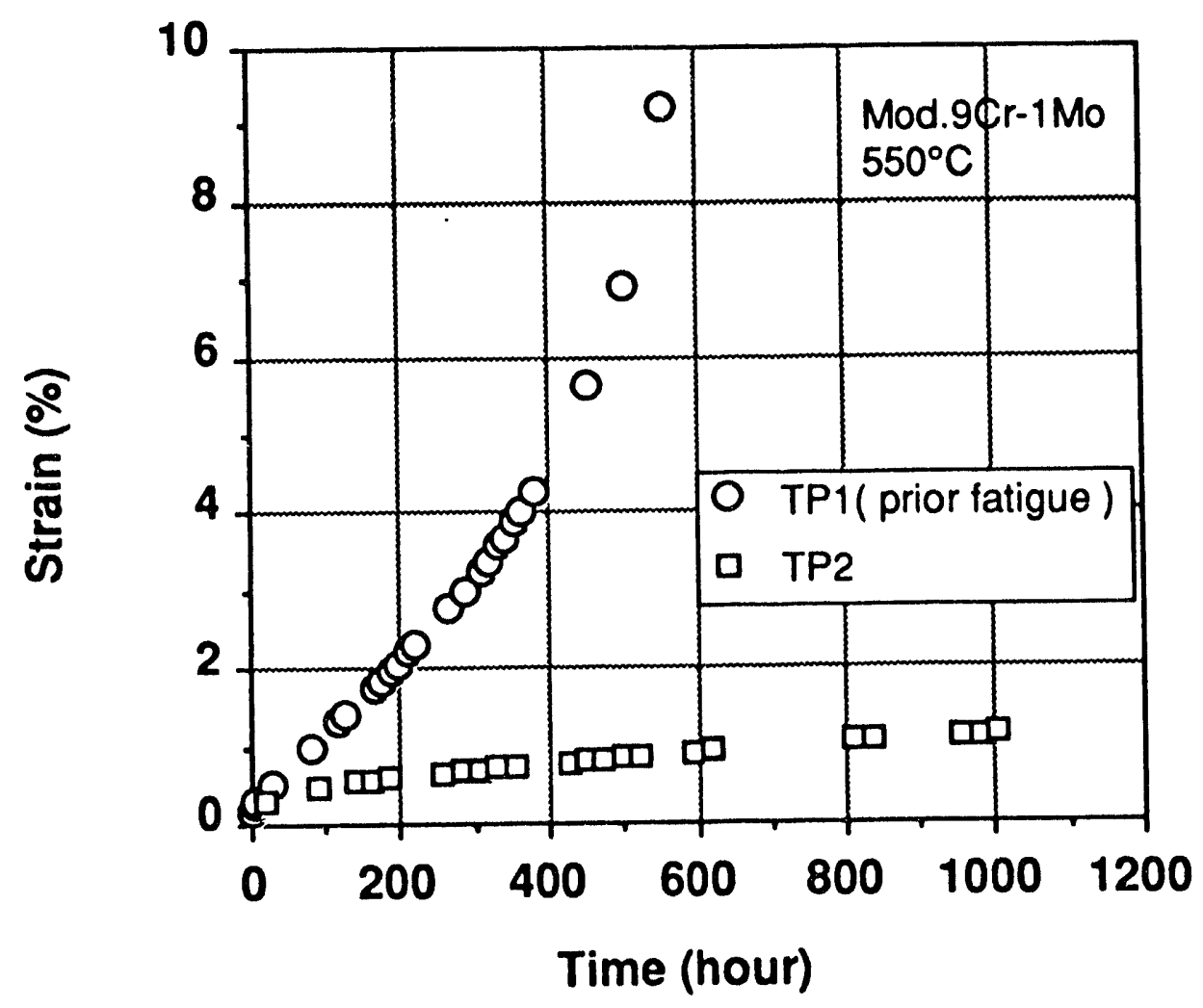

Fig. 3.1. Strain vs Time. CRIEPI Exploratory Deformation Tests. 


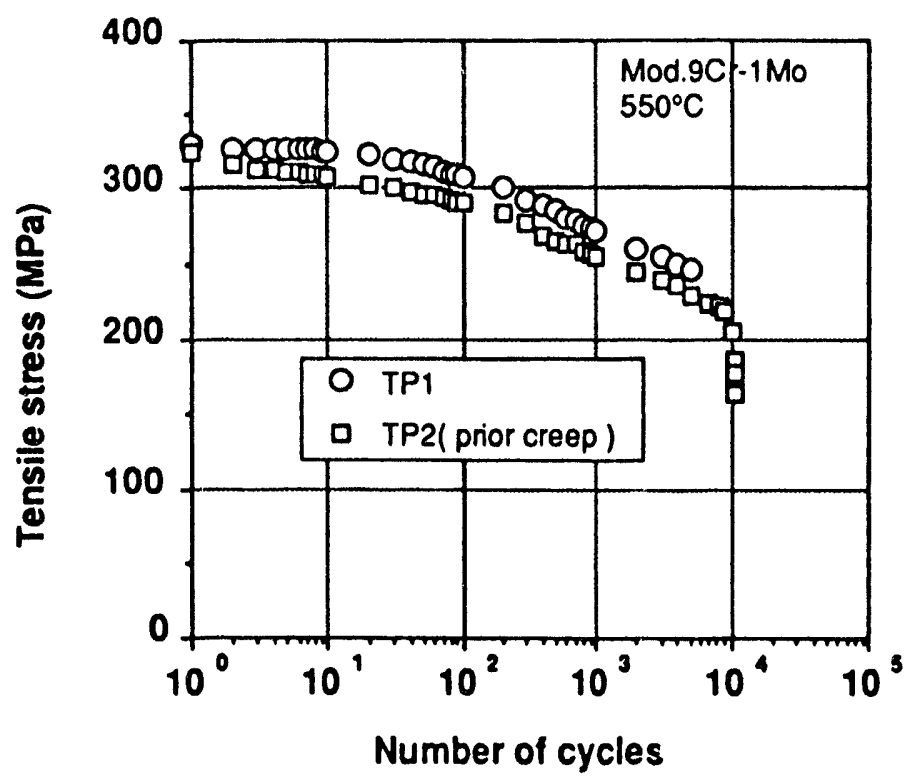

Fig. 3.2. Variation in Maximum Tensile Stress with the Number of Cycles in Exploratory Deformation Tests.

\section{UNIFIED CONSTITUTIVE EQUATIONS FOR INELASTIC ANALYSIS OF MODIFIED $9 \mathrm{Cr}-1 \mathrm{MO}$ STEEL}

\subsection{BASIC MODEL RECOMMENDATIONS}

Recent experimental investigations [1] revealed that in the 25$600^{\circ} \mathrm{C}$ temperature range modified $9 \mathrm{Cr}-1 \mathrm{Mo}$ steel exhibits strong strain rate sensitivity, significant strain softening, and cyclic softening. The constitutive framework based on classical decomposition into time- and rate-independent plasticity and timedependent creep does not provide an adequate representation of these phenomena. It is particularly noteworthy that the pressure vessel and piping components constructed from modified $9 \mathrm{Cr}-1$ Mo steel may be subjected to complex, and at times severe, thermomechanical loading histories. Thus it is essential to have adequate predictions of the material behavior over a range of temperatures. In addition, a constitutive model framework should be adaptable to several different ferritic steels. A viscoplastic model [2] is recommended which addresses these issues. 


\subsection{MATHEMATICAL FRAMEWORK OF THE MODEL}

The following model structure is adopted for the $25-600^{\circ} \mathrm{C}$ temperature range. The rate sensitivity function is written as:

$$
\dot{p}=G\left(\frac{\langle\Sigma-\kappa\rangle}{D}, T\right) \theta(T)
$$

where the brackets signify

$$
\langle\Sigma-\kappa\rangle=\left(\begin{array}{l}
0 ; \Sigma-\kappa \leq 0 \\
\Sigma-\kappa ; \Sigma-\kappa>0
\end{array}\right)
$$

For convenience multiplicative separation into stress-dependent and temperature-dependent functions is chosen. However, temperature dependence is also included in the function $G$. The function $\theta$ is analogous to the diffusivity parameter for creep.

Kinematic hardening is introduced via superposition of nonlinear kinematic hardening rules of the Armstrong-Frederick type as proposed by Chaboche and coworkers. Thus the general form of the growth law for the back stress is given by

$$
\dot{\alpha}_{1}=C\left[b_{1} n-\alpha_{i}\right] \dot{p}-R_{1} \frac{\alpha_{1}}{\left\|\alpha_{1}\right\|} ; \quad \alpha=\sum_{i=1}^{N_{2}} \alpha_{1} .
$$

This formulation gives an adequate representation of the Bauschinger effect and performs well for cyclic, nonproportional loading conditions.

Evolution of the generic isotropic hardening variable is written as:

$$
\dot{x}_{1}=\mu_{i}\left[\bar{x}_{1}-\chi_{1}\right] \dot{j} ; \quad \chi=\sum_{i=1}^{N_{x}} x_{1} .
$$

This variable represents an isotropic increase or decrease in isothermal flow stress with accumulated inelastic strain. the 
isotropic hardening/softening may be partitioned between the $\omega_{i}, k$ and $D$ as follows:

$$
\begin{gathered}
b_{1}=b_{1}^{0}(T)+\sqrt{\frac{2}{3}} \omega_{1} \chi \\
k=\xi \chi+\kappa_{0} \\
D=1+\frac{\beta \chi}{G^{-1}\left[\dot{p}_{0} / \theta(T)\right]}
\end{gathered}
$$

and

$$
\sum_{i=1}^{N} \omega_{1}+\xi+\beta=1
$$

where $\dot{p}_{0}$ is the inelastic strain rate (assumed to be approximately constant) of the test and $G^{-1}$ is the functional inverse of $G$ at the test temperature. Parameters $\omega_{i}, \xi$ and $\beta\left(0 \leq \omega_{i} \leq 1,0 \leq \xi \leq 1,0 \leq \beta \leq 1\right)$ are the fractions of $\chi$ to be incorporated in the $\omega_{i}, \kappa$ and $D$, respectively.

It is useful to consider a geometric interpretation of the model. A bounding or saturation surface with the radius $R^{*}$ is defined in the deviatoric stress space (bounding surface construction in the deviatoric stress space is shown in Fig. 4.1, and components of the asymptotic effective stress in the uniaxial monotonic case are shown in Fig. 4.2). The radius $R^{*}$ is given by:

$$
R^{\prime}=\sqrt{\frac{3}{2}} \sum_{i=1}^{N_{B}} b_{i}+\Sigma .
$$

This quantity represents the saturation or the asymptotic value of the effective stress for a constant strain rate for a proportional loading path. 


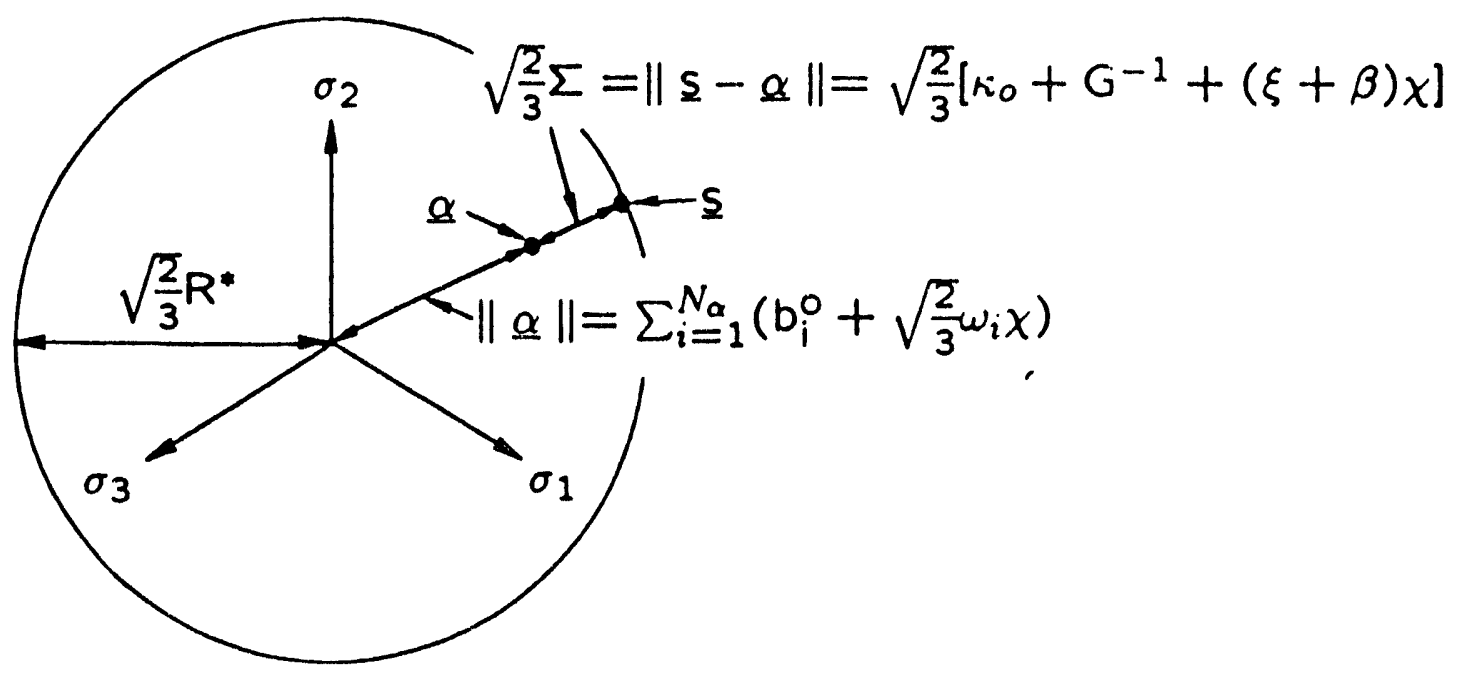

Fig. 4.1. Illustration of the bounding or saturation surface associated with a proportional loading segment in deviatoric stress space.

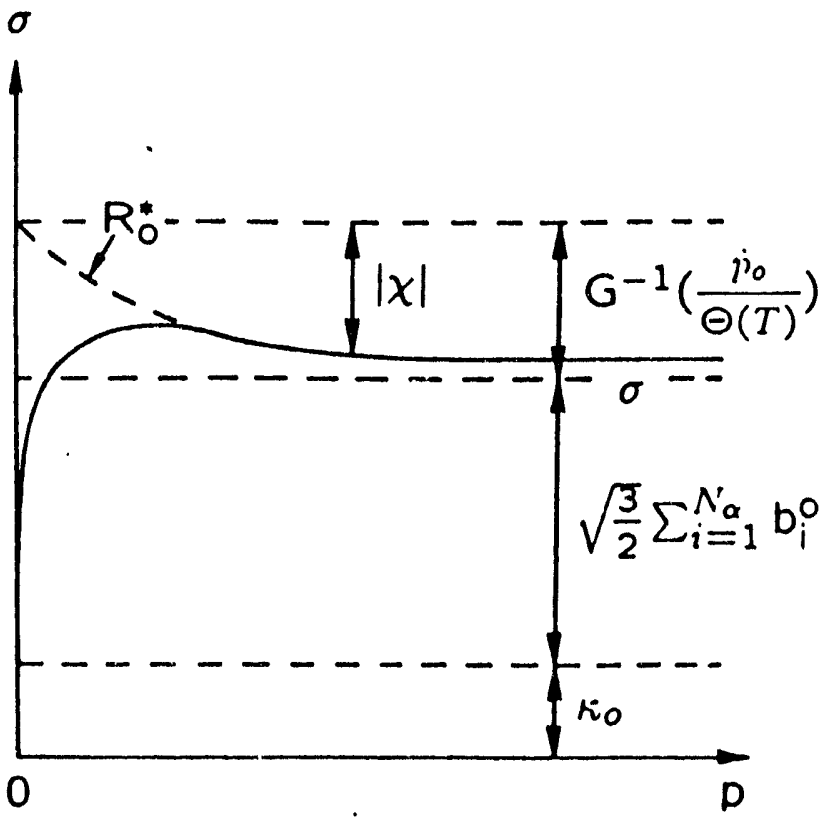

Fig. 4.2. Schematic illustration of the various components of the model framework for the constant strain-rate, monotonic, uniaxial case. 
Therefore, if $\dot{p}_{0}$ is the effective inelastic strain rate and $R_{0}^{*}$ and $\Sigma_{0}$ are, respectively, the radius of the bounding surface and the effective overstress corresponding to this stress rate, then

$$
R_{0}^{\cdot}=\sqrt{\frac{3}{2}} \sum_{i=1}^{N_{2}} b_{i}+\Sigma_{0}=\sqrt{\frac{3}{2}} \sum_{i=1}^{N_{s}} b_{i}+D G^{-1}\left(\frac{\dot{p}_{0}}{\theta(T)}\right)+\kappa .
$$

Combining Eqns. (4.5-4.8) and Eq. (4.10), we obtain:

$$
R_{0} \cdot=\sqrt{\frac{3}{2}} \sum_{i=1}^{N_{0}} b_{1}^{0}(T)+G^{-1}\left(\frac{\dot{P}_{0}}{\theta(T)}\right)+x+\chi .
$$

The condition $\dot{x}>0$ corresponds to isotropic hardening; the condition $\dot{\chi}<0$, to isotropic softening; and the condition $\dot{x}=0$, to an isotropically neutral material.

Within this framework the analyst can use experimental data to fit strain-rate sensitivity and isotropic hardening/softening rules without necessarily knowing the exact contritutions of each flow stress component. Values of $\omega_{i}, \xi$ and $\beta$ can then be selected to best fit the transient material responses.

\subsection{MODEL FITTING PROCEDURE}

\subsubsection{STRAIN RATE SENSITIVITY, TEMPERATURE DEPENDENCE AND FLOW SOFTENING BEHAVIOR}

The schematic diagram in Fig. 4.3 illustrates the method recommended for determining strain rate sensitivity and temperature dependence. Monotonic test data are used and values of a zero strair "intercept stress" are determined which correspond to $R^{*}$ at $p=0$. 


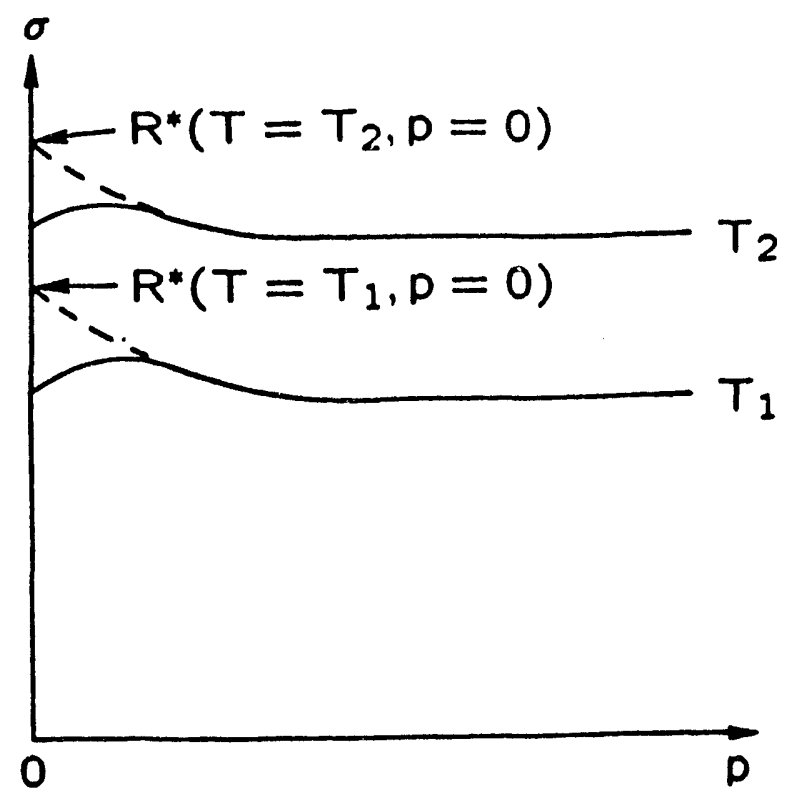

Fig. 4.3. Illustration of the determination of the zero-strain intercept stress which was taken to equal the bounding-surface radius at zero accumulated inelastic strain.

The following correlations were obtained from a least squares fit of monotonic stress-strain data at a strain rate of $6.7 \times 10^{-5} \mathrm{~s}^{-1}$ :

$$
\begin{aligned}
R^{\circ}= & 574.1 e^{101.4 / T} ; \quad T<723^{\circ} \mathrm{K} \\
& 1582\left[\ln \left(\frac{1}{\mathrm{~T}}\right)+7\right] ; T \geq 723^{\circ} \mathrm{K}
\end{aligned}
$$

where $T$ is the absolute temperature in $\mathrm{K}$. Correlations from data at different strain rates are given below:

$$
\begin{aligned}
R^{\circ}=778 \dot{\varepsilon}^{0.082} ; & T=873 K \\
752 \dot{\varepsilon}^{0.054} ; & T=81 K \\
778 \dot{\varepsilon}^{0.035} ; & T=773 K .
\end{aligned}
$$


The correlations in Eq. (4.13) are presented in Fig. 4.4.

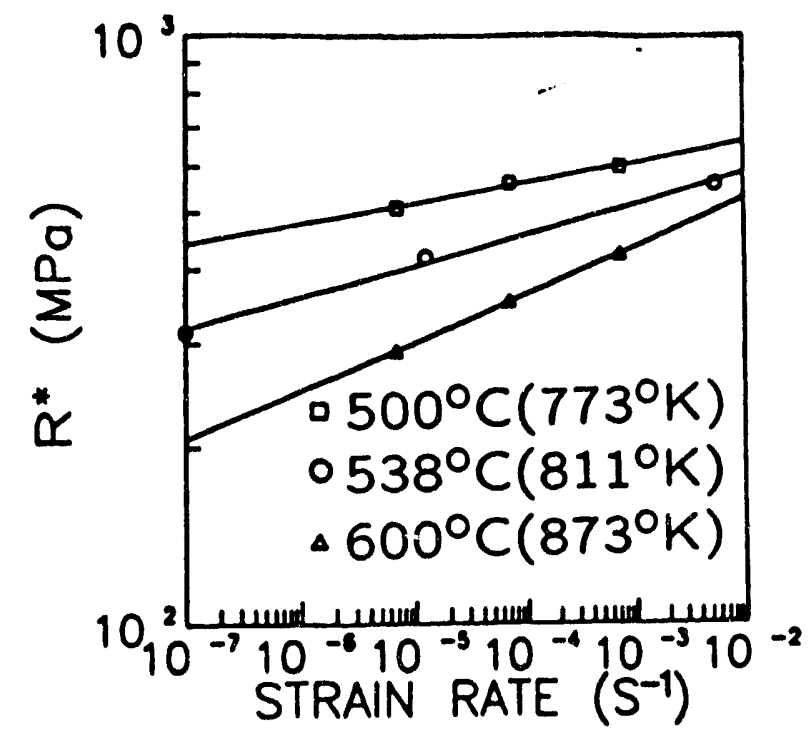

Fig. 4.4. Strain-rate dependence of the bounding surface radius as determined from tests at two temperatures. The solid lines are the correlations given by Eq. (4.13).

For simplification the bounding surface radius is assumed to be of the form:

$$
R^{*}=A(T) \dot{p}^{m(T)} \theta^{\prime}(T)
$$

where a power law relationship for strain rate dependence is assumed to fit the data, at least for relatively low strain rates. Based on Eq. (4.12) we can state:

$$
\begin{aligned}
\theta^{\prime}(T)=\theta^{101.4 / T} ; & T<723 K \\
{\left[\ln \left(\frac{1}{T}\right)+7\right] ; } & T \geq 723 K .
\end{aligned}
$$


A flow softening equation is determined by fitting the stress decrease (from the intercept stress) vs accumulated inelastic strain for the monotonic stress-strain curve obtained at the strain rate of $6.7 \times 10^{-5} \mathrm{~s}^{-1}$ and at $T=873 \mathrm{~K}$. The following representation of the isotropic hardening gave good approximations of both the monotonic and cyclic behaviors:

$$
\begin{gathered}
x=\mathrm{R}^{\cdot}-\sigma_{1}=\chi_{1}+\chi_{2} \\
x_{1}=\bar{\chi}_{1}\left(1-e^{-\mu_{1} p}\right) ; \quad \dot{\chi}_{1}=\mu_{1}\left(\bar{\chi}_{1}-\chi_{1}\right) \dot{\mathrm{p}} \\
\chi_{2}=\bar{\chi}_{2}\left(1-e^{-\mu_{2} \mathrm{p}}\right) ; \quad \dot{\chi}_{2}=\mu_{2}\left(\bar{\chi}_{2}-\chi_{2}\right) \dot{\mathrm{p}}
\end{gathered}
$$

where $\sigma_{f}$ is the uniaxial flow stress in a monotonic test or stress amplitude in a cyclic test and $p$ is the corresponding accumulated inelastic strain. The constants were established as:

$$
\begin{array}{ll}
\bar{\chi}_{1}=-65 \mathrm{Mpa} ; & \mu_{1}=30 \\
\bar{\chi}_{2}=-15 \mathrm{Mpa} ; & \mu_{2}=0.3 .
\end{array}
$$

\subsubsection{KINEMATIC HARDENING BEHAVIOR}

Kinematic hardening behavior at a given temperature is specified by choosing $N_{\alpha}, b_{i}, C_{i}$, and $R_{i}$. For constant strain rate cycling or monotonic tests at moderate strain rates the terms $R_{i} \alpha_{i}$ Eq.(4.3) can be neglected.

To simplify the fitting procedure, the $C_{i}$ are assumed to be independent of temperature, and $N_{\alpha}=3, \kappa_{0}=0$ and $\xi=0$ are chosen. Then the $b_{i}{ }^{\circ}(T)$ and $C_{i}$ are selected by fitting the monotonic test data at the strain rate of $6.7 \times 10^{-5} \mathrm{~s}^{-1}$ for the temperature range $298 \mathrm{~K} \leq \mathrm{T} \leq$ $600 \mathrm{~K}$. With $\mathrm{N}_{\alpha}=3$ and $\kappa_{0}=\xi=0$, Eq. (4.9) becomes: 


$$
R^{\cdot}=\sqrt{\frac{3}{2}} \sum_{i=1}^{3}\left[b_{i}^{0}(T)+\sqrt{\frac{2}{3}} \omega_{i} \chi\right]+\Sigma
$$

Results of short term relaxation tests permit another simplifying assumption: $\omega_{i}=0$. Then the attenuated effective overstress can be expressed as:

$$
\frac{\Sigma}{D}=G^{-1}\left(\frac{\dot{p}}{\theta}, T\right)=A(T) \dot{p}^{m(T)} \theta^{\prime}(T)-\sqrt{\frac{3}{2}} \sum_{i=1}^{3} b_{i}^{0}(T)-\chi .
$$

For the uniaxial case, the kinematic hardening rule may be integrated explicitly yielding:

$$
\alpha_{1}=\sqrt{\frac{3}{2}} b_{1}\left(1-e^{-c_{1} p}\right) ; \quad \alpha=\sum_{i=1}^{3} \alpha_{1}
$$

where $\alpha_{i}=\left(\alpha_{11}\right)_{i}$ is the ith uniaxial back stress. Assuming that the viscoplastic strain rate quickly approaches the total strain rate in monotonic tests, one may write:

$$
\sigma=\sum_{i=1}^{3} \alpha_{1}+D G^{-1}\left(\frac{\dot{p}}{\theta}, T\right)
$$

where $G^{-1}$ is computed using Eq. (4.15) with $\dot{p}=\dot{\varepsilon}$ the drag variable $D$ is calculated from Eq. (4.7) with Eqns. (4.16-4.18) and $\beta=1$. The $\alpha_{i}$ are computed with Eq. (4.21). Since $\omega_{i}=0$ and $b_{i}=b_{i}{ }^{\circ}(T)$, it is possible to fit constant strain rate, monotonic tests as a function of temperature by choosing appropriate functions $b_{i}{ }^{\circ}(T)$. To find suitable $b_{i}{ }^{\circ}(T)$ it was assumed that:

$$
\sqrt{\frac{3}{2}} \sum_{i=1}^{3} b_{i}^{0}(T)=B^{0} \theta^{\prime}(T)
$$




\subsubsection{OVERSTRESS-INELASTIC STRAIN RATE - TEMPERATURE RELATIONSHIP}

A suitable function relating effective overstress to inelastic strain rate is determined based on Eqns. (4.20) and (4.23):

$$
\Sigma_{1}=\frac{\Sigma}{D}=A(T) \dot{p}^{m(T)} \theta^{\prime}(T)-B^{0} \theta^{\prime}(T)-\chi
$$

We may choose $D=1$ corresponding to $\chi=0$ (for which $A, m$, and $\theta^{\prime}$ were determined) so that:

$$
\frac{\Sigma_{1}}{\theta^{\prime}(T)}=A(T) \dot{p}^{m(T)} \theta^{\prime}-B^{0}
$$

Using Eqns. (4.12-4.14) and (4.25), the following correlations were found for 773,811 , and $873 \mathrm{~K}$ :

$$
\begin{gathered}
\frac{\Sigma_{1}}{\theta^{\prime}(T)}=A^{\prime} \dot{p}^{m^{\prime}} \\
A^{\prime}=1470 ; \quad m^{\prime}=0.088 ; \quad T=773 \mathrm{~K} \\
A^{\prime}=2268 ; \quad m^{\prime}=0.154 ; \quad T=811 \mathrm{~K} \\
A^{\prime}=4747 ; \quad m^{\prime}=0.220 ; \quad T=873 \mathrm{~K} .
\end{gathered}
$$

Functional forms for $A^{\prime}$ and $m^{\prime}$ are taken to fit these points:

$$
\begin{aligned}
A^{\prime}(T) & =3.905 \times 10^{7} \theta^{-7875 / T} \\
m^{\prime}(T) & =-1.052 \ln \left(\frac{1}{T}\right)-6.901
\end{aligned}
$$

for $T \geq 723 \mathrm{~K}$. For $T<723 \mathrm{~K}$ a constant value of $m^{\prime}=0.024$ was assumed and $A^{\prime}=263.2$ was determined by matching the value of overstress at $723 \mathrm{~K}$ using the low temperature $\theta^{\prime}$ function. Then inversion of Eq. (4.26) yields the functions $G$ and $\theta$ : 


$$
\dot{p}=\left(\frac{\Sigma}{A^{\prime} \theta^{\prime}}\right)^{1 / m^{\prime}}=\left(\frac{\Sigma}{D}\right)^{1 / m^{\prime}} \theta \text {, }
$$

where

$$
\theta(T)=\left(A^{\prime} \theta\right)^{-1 / m^{\prime}}
$$

\subsubsection{THERMAL RECOVERY TERM}

Generally, thermal recovery terms are determined so as to match observed material behavior at very low strain rates, during long hold periods at elevated temperature, etc. Within the present constitutive framework preliminary thermal recovery functions have been introduced in order to obtain realistic creep rates at elevated temperatures. These are:

$$
R_{1}=C_{1} b_{1} \frac{\left(\sqrt{\frac{3}{2}}\left\|\alpha_{1}\right\|\right)^{1 / m^{\prime}}}{K_{1}} \theta .
$$

\subsection{SUMMARY OF THE MODEL}

A summary of the model fitted to the available isothermal data is presented below:

$$
\begin{gathered}
\dot{\varepsilon}^{n}=\sqrt{\frac{3}{2}}\left(\frac{\Sigma}{D}\right)^{1 / m^{\prime}} \text { on }=\sqrt{\frac{3}{2}} \dot{p} n \\
\dot{\alpha}_{1}=C\left[b_{1} n-\alpha_{1}\right] \dot{p}-R_{1} \frac{\alpha_{1}}{\left\|\alpha_{1}\right\|} ; \quad \alpha=\sum_{i=1}^{3} \alpha_{1} \\
\dot{\chi}_{1}=\mu_{1}\left(\bar{\chi}_{i}-\chi_{1}\right) \dot{p}_{i} \quad \chi=\sum_{i=1}^{3} \chi_{i}
\end{gathered}
$$




$$
\begin{gathered}
D=1+\frac{\chi}{A^{\prime} \theta^{\prime} \dot{p}_{0}^{m^{\prime}}} ; \quad \dot{p}_{0}=6.7 \times 10^{-5} \mathrm{~s}^{-1} \\
\Sigma=\sqrt{\frac{3}{2}}\|s-\alpha\|_{i} n=\frac{s-\alpha}{\|s-\alpha\|} \\
\theta=\left(A^{\prime} \theta\right)^{-v / m^{\prime}} \\
R_{1}=C_{1} b_{1} \frac{\left(\sqrt{\frac{3}{2}}\|\alpha\|\right)^{1 / m^{\prime}}}{K_{1}} \theta .
\end{gathered}
$$

A summary of material constants and temperature dependent parameters is given in Tables 4.1 and 4.2.

Table 4.1. Values of Parameters in Inelastic Deformation Model.

\begin{tabular}{|c|c|c|c|}
\hline$\sqrt{\frac{3}{2}} b_{1}^{\circ}(M P a)$ & $\sqrt{\frac{3}{2}} b_{2}^{\circ}(M P a)$ & $\sqrt{\frac{3}{2}} b_{j}^{\circ}(M P a)$ & $\begin{array}{c}\text { Temperature } \\
\left({ }^{\circ} \mathrm{K}\right)\end{array}$ \\
\hline 150.0 & 117.5 & 266.6 & 298 \\
\hline 150.0 & 117.5 & 236.8 & 364 \\
\hline 150.0 & 117.5 & 188.7 & 573 \\
\hline 150.0 & 117.5 & 173.3 & 673 \\
\hline 150.0 & 164.1 & 81.4 & 723 \\
\hline 146.5 & 120.7 & 64.8 & 773 \\
\hline 141.1 & 82.4 & 48.9 & 823 \\
\hline 105.0 & 83.6 & 27.9 & 873 \\
\hline & $C_{1}=7000$ & $C_{2}=500$ & $C_{3}=37.5$ \\
\hline
\end{tabular}


Table 4.2. Values of Pararneters in Inelastic Deformation Model.

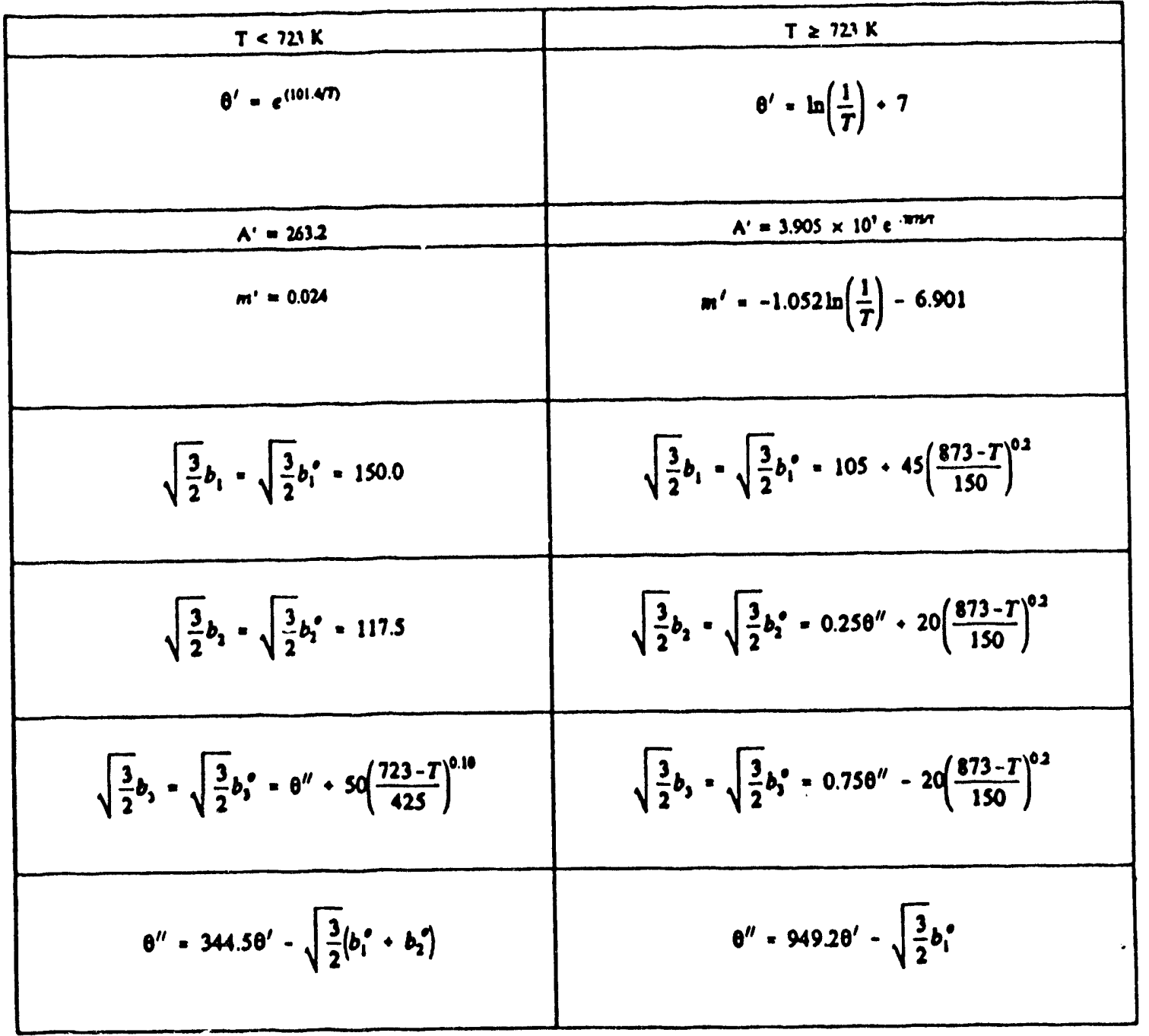




\section{AXIAL FATIGUE AND CREEP-FATIGUE TESTS}

\subsection{LOW CYCLE FATIGUE TESTS}

\section{EPRI}

Twelve isothermal axial strain controlled cyclic tests have been performed. Thin-walled tubular tesi specimens were machined to the specifications in Fig. 5.1. Test temperatures were 20,300, and $500^{\circ} \mathrm{C}$. Strain ranges were $0.5,0.7,1.0$, and $1.4 \%$. A srain rate of $10^{-3} \mathrm{~s}^{-1}$ and a triangular waveform were used in all tests. Failure was defined as a $50 \%$ reduction in maximum cyclically saturated axial load.

Resuits are presented in Table 5.1. It is seen that fatigue life decreases with increasing temperature. This decrease is significant for lower strain ranges and less dramatic for the higher ones. Added to Table $\mathbf{5 . 1}$ for comparison are results of two axial tests performed at $550^{\circ} \mathrm{C}$ with a strain rate of $10^{-3} \mathrm{~s}^{-1}$ and strain ranges of 0.7 and $1.0 \%$. It is seen that the results obtained at $550^{\circ} \mathrm{C}$ are consistent with those described above.

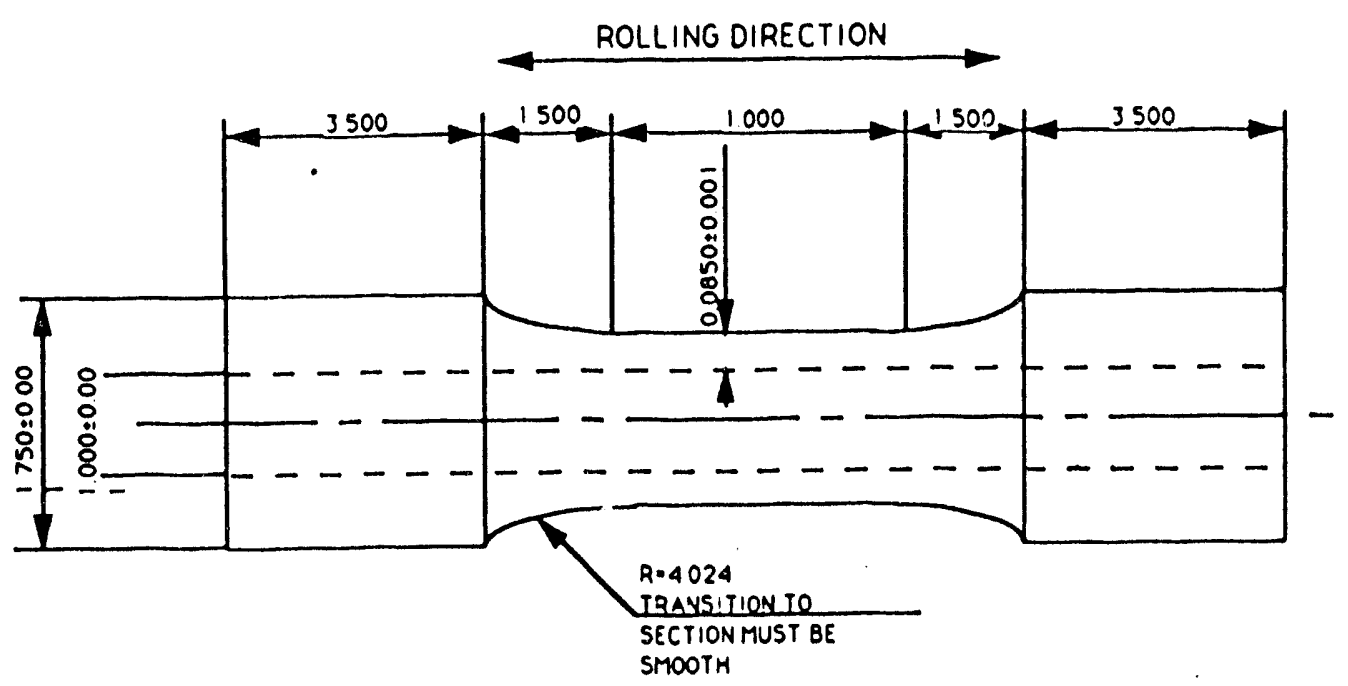

UNIT: I In.

Fig. 5.1. EPRI/ORNL Deformation Specimen. 
Table 5.1. EPRI Axial Low Cycle Fatigue Tests, $\dot{\varepsilon}=10^{-3} \mathrm{~s}^{-1}$.

\begin{tabular}{ccc}
\hline $\begin{array}{c}\text { Temperature } \\
\left({ }^{\circ} \mathrm{C}\right)\end{array}$ & $\begin{array}{c}\text { Total Strain Range } \\
(\%)\end{array}$ & $\begin{array}{c}\text { Cycles to Failure } \\
\text { (cycles) }\end{array}$ \\
\hline 20 & 0.5 & 25,640 \\
& 0.7 & 7,886 \\
& 1.0 & 2,611 \\
& 1.4 & 1,027 \\
\hline 300 & 0.5 & 16,630 \\
& 0.7 & 4,454 \\
& 1.0 & 1,448 \\
& 1.4 & 783 \\
\hline 500 & & 8,621 \\
& 0.5 & 2,888 \\
& 0.7 & 1,182 \\
& 1.0 & 342 \\
\hline 550 & 1.4 & 1,574 \\
\hline
\end{tabular}

\section{CRIEPI}

Conditions of the strain controlled uniaxial fatigue tests are summarized in Table 5.2. A servo-electro-hydraulic fatigue machine together with an induction heater was employed for testing. Specimens were machined to the specifications in Fig. 5.2. Fatigue failure was defined as a $25 \%$ reduction in cyclically saturated axial load.

Test results are given in Table 5.3. The total strain range vs number of cycles is plotted in Fig. 5.3. The effect of temperature on the low cycle fatigue life appears to be small for a large strain range, however, it increases significantly for smaller strain ranges. The 
considerable decrease in fatigue life with increasing temperatures observed for lower strain ranges is attributed to an increase with temperature of inelastic strain range.

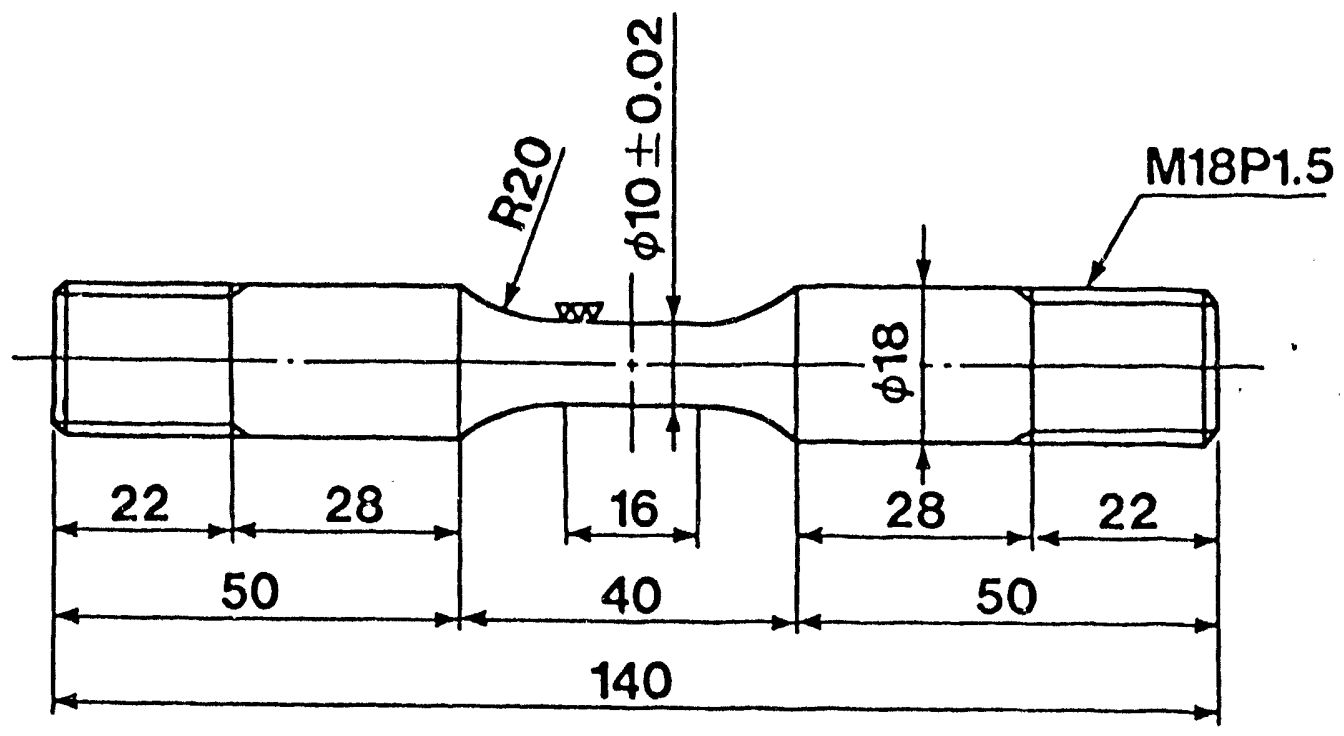

Fig. 5.2. CRIEPI Axial Fatigue Specimen.

Table 5.2. CRIEPI Axial Fatigue Tests - Test Conditions.

$\dot{\varepsilon}=0.1 \% / \mathrm{sec}$

\begin{tabular}{|c|c|c|c|c|}
\hline $\mathrm{T}\left({ }^{\circ} \mathrm{C}\right)(\%$ & 0.5 & 0.7 & 1.0 & 1.4 \\
\hline 200 & 0 & 0 & 0 & 0 \\
\hline 400 & 0 & 0 & 0 & 0 \\
\hline 550 & 0 & 0 & 0 & 0 \\
\hline 600 & & 0 & 0 & 0 \\
\hline
\end{tabular}


Table 5.3. CRIEPI Axial Fatigue Tests - Results.

\begin{tabular}{|c|c|c|c|}
\hline $\begin{array}{c}\text { Temperature } \\
\left({ }^{\circ} \mathrm{C}\right)\end{array}$ & $\begin{array}{l}\text { Tolal strain } \\
\text { range } \\
(\%)\end{array}$ & $\begin{array}{c}\text { Inelastic strain } \\
\text { range } \\
(\%)\end{array}$ & $\begin{array}{l}\text { Number of } \\
\text { cycles to } \\
\text { failure } \\
\text { (cycles) }\end{array}$ \\
\hline \multirow{4}{*}{200} & 1.4 & 1.030 & 2460 \\
\hline & 1.0 & 0.631 & 3400 \\
\hline & 0.7 & 0.364 & 12840 \\
\hline & 0.5 & 0.207 & 33050 \\
\hline \multirow{4}{*}{400} & 1.4 & 1.035 & 1786 \\
\hline & 1.0 & 0.658 & 3076 \\
\hline & 0.7 & 0.416 & 8160 \\
\hline & 0.5 & 0.176 & 15800 \\
\hline \multirow{4}{*}{550} & 1.4 & 1.149 & 1385 \\
\hline & 1.0 & 0.786 & 3120 \\
\hline & 0.7 & 0.482 & 4280 \\
\hline & 0.5 & 0.320 & 10960 \\
\hline \multirow{4}{*}{600} & 1.4 & 1.242 & 2050 \\
\hline & 1.0 & 0.844 & 3600 \\
\hline & 0.7 & 0.528 & 4620 \\
\hline & 0.5 & 0.318 & 7290 \\
\hline
\end{tabular}




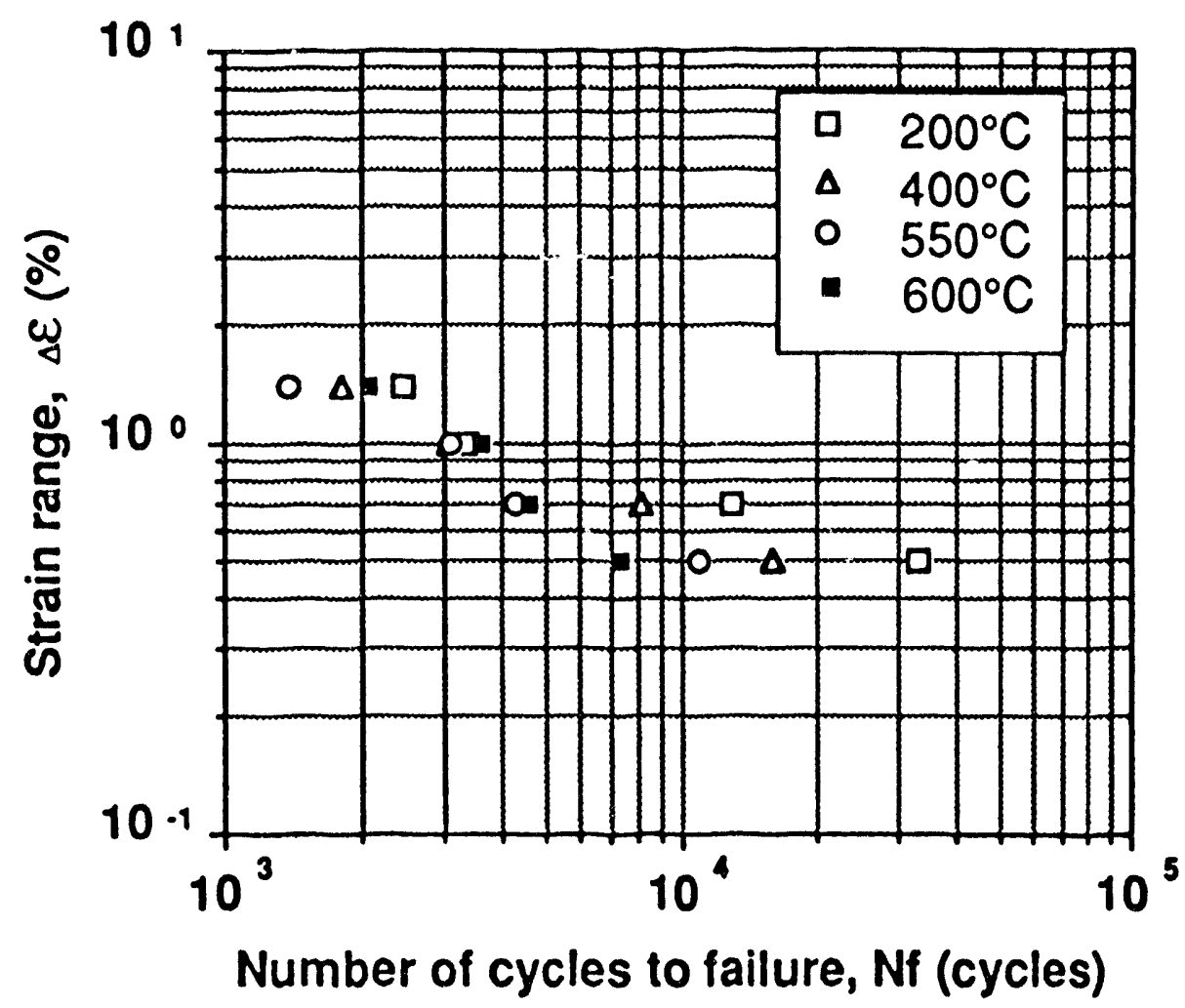

Fig. 5.3. Uniaxial Low Cycle Fatigue Results, Total Strain Range vs the Number of Cycles to Failure.

\subsection{VARIABLE STRAIN RATE FATIGUE TESTS}

\section{EPRI}

Nine variable strain rate fatigue tests were conducted at $550^{\circ} \mathrm{C}$ and strain ranges of $0.7,1.0$, and $1.4 \%$. For each strain range three different tests were performed: (1) constant strain rate test, strain rate $=10^{-5} \mathrm{~s}^{-1} ;$ (2) variable strain rate test with a tension going strain rate of $10^{-3} \mathrm{~s}^{-1}$, and a compression going strain rate of $10^{-5} \mathrm{~s}^{-1}$; (3) variable strain rate test with a tension going strain rate of $10^{-5}$ $\mathrm{s}^{-1}$, and a compression going strain rate of $10^{-3} \mathrm{~s}^{-1}$. Thin-walled tubular test specimens, shown in Fig. 5.1, were used.

Test results are summarized in Table 5.4. When contrasted with the results obtained at $550^{\circ} \mathrm{C}$ at a strain rate of $10^{-3} \mathrm{~s}^{-1}$ (see Table 5.1), specimens tested at a strain rate of $10^{-5} \mathrm{~s}^{-1}$ exhibit considerably shorter fatigue lives. Thus fatigue life at $550^{\circ} \mathrm{C}$ appears to decrease with decreasing strain rate. It is also seen that for all strain ranges 
specimens tested at a constant rate of $10^{-5} \mathrm{~s}^{-1}$ exhibited shorter fatigue lives than those tested with different tension and compression going strain rates. Thus it would appear that introduction of a higher strain rate into the loading cycle may prolong fatigue life. For a given strain range, specimens tested with slower tension going rates exhibited longer fatigue lives than the specimens tested with faster tension going rates.

Table 5.4. EPRI Variable Strain Rate Fatigue Tests; $T=550^{\circ} \mathrm{C}$.

\begin{tabular}{cccc}
\hline $\begin{array}{c}\text { Total Strain } \\
\text { Range } \\
(\%)\end{array}$ & $\begin{array}{c}\text { Tension Going } \\
\text { Strain Rate } \\
\left(\mathrm{s}^{-1}\right)\end{array}$ & $\begin{array}{c}\text { Compression Going } \\
\text { Strain Rate } \\
\left(\mathrm{s}^{-1}\right)\end{array}$ & $\begin{array}{c}\text { Cycles to } \\
\text { Failure } \\
\text { (cycles) }\end{array}$ \\
\hline 0.7 & 10.5 & 10.3 & 2,135 \\
0.7 & 10.3 & 10.5 & 1,327 \\
0.7 & 10.5 & 10.5 & 630 \\
1.0 & 10.5 & 10.3 & 772 \\
1.0 & 10.3 & 10.5 & 548 \\
1.0 & 10.5 & 10.5 & 337 \\
1.4 & 10.5 & 10.3 & 361 \\
1.4 & 10.3 & 10.5 & 218 \\
1.4 & 10.5 & 10.5 & 250 \\
\hline
\end{tabular}

Therefore, upon comparing results for a given strain range, a conclusion can be drawn that the lowest strain rate $\left(10^{-5} \mathrm{~s}^{-1}\right)$ yields the shortest fatigue life. Introduction of a faster strain rate $\left(10^{-3} \mathrm{~s}^{-}\right.$ ${ }^{1)}$ into the fatigue cycle (either in tension or in compression) leads to an increase in fatigue life. Fatigue life obtained with the fast $\left(10^{-3} \mathrm{~s}^{-}\right.$ 1) tension going rate is shorter than that obtained with the fast $(10.3$ $\left.s^{-1}\right)$ compression going rate. Thus, introduction of the faster strain rate $\left(10^{-3} \mathrm{~s}^{-1}\right)$ in compression produces lonyer fatigue life than obtained with the constant slow strain rate $\left(10^{-5} \mathrm{~s}^{-1}\right)$ or with the 
slow compression going strain rate $\left(10^{-5} \mathrm{~s}^{-1}\right)$. It is seen from comparison of results in Table 5.4 with those in Table 5.1 that the constant strain "fast" rate $\left(10^{-3} \mathrm{~s}^{-1}\right)$ fatigue t3sts produce the longest fatigue lives.

\subsection{CREEP-FATIGUE TESTS}

\section{CRIEPI}

Creep-fatigue tests with tensile hold times, compressive hold times, and both tensile and compressive hold times were performed using an electro-mechanical creep-fatigue testing machine. Tensile specimens were machined to the specifications shown in Fig. 5.4. Test conditions are summarized in Table 5.5, test results are given in Table 5.6. As in the CRIEPI low cycle fatigue tests, failure was defined as a $25 \%$ reduction in cyclically saturated axial load. Fracture surfaces of several failed specimens were studied under a scanning electron microscope (SEM).

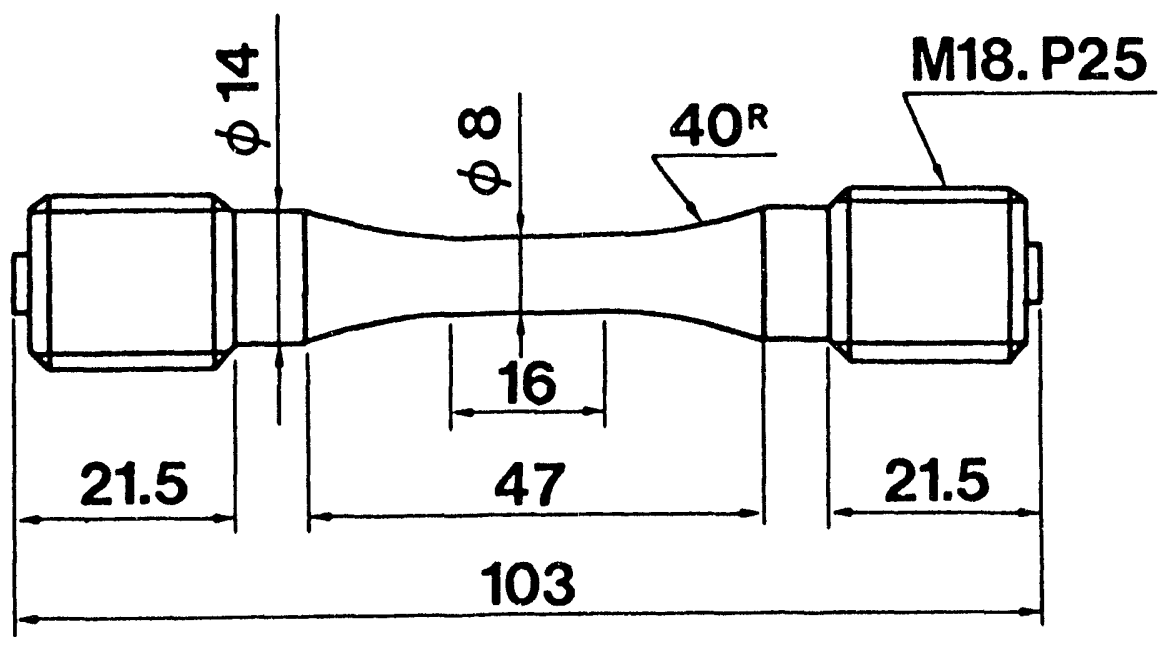

Fig. 5.4. CRIEPI Axial Creep-Fatigue Specimen. 
Table 5.5. CRIEPI Axial Creop-Fatigue Tests - Test Conditions.

$\Delta \varepsilon=0.5 \%$
\begin{tabular}{|c|c|c|c|}
\hline $\begin{array}{l}\text { HOLD } \\
\text { TIME (min) }\end{array}$ & TH & $\mathrm{CH}$ & $\mathrm{TCH}$ \\
\hline 10 & 0 & 0 & 0 \\
\hline
\end{tabular}

$$
\Delta \varepsilon=1.0 \% \quad T=550^{\circ} \mathrm{C}
$$

\begin{tabular}{|c|c|c|c|}
\hline $\begin{array}{l}\text { HOLD } \\
\text { TIME (min) }\end{array}$ & TH & CH & TCH \\
\hline 10 & & & 0 \\
\hline 60 & & & \\
\hline
\end{tabular}




\begin{tabular}{|c|c|c|c|c|c|c|c|c|c|c|}
\hline TP No. & $\begin{array}{l}\text { Hol } \\
\text { Tension } \\
\text { (min) }\end{array}$ & $\begin{array}{l}\text { time } \\
\text { Compres- } \\
\text { sion } \\
\text { (min) }\end{array}$ & $\begin{array}{l}\text { Total strain } \\
\text { range } \\
(\%) \\
\end{array}$ & $\begin{array}{c}\text { Inelastic } \\
\text { strain range } \\
(\%) \\
\end{array}$ & $\begin{array}{l}\text { Number of } \\
\text { cycles to } \\
\text { failure } \\
\text { (cycles) }\end{array}$ & $\begin{array}{l}\text { Maximum } \\
\text { stress at } \\
\text { mid-life } \\
(\mathrm{MPa})\end{array}$ & $\begin{array}{c}\text { Minimum } \\
\text { stress at } \\
\text { mid-life } \\
\text { (Mpa) }\end{array}$ & $\begin{array}{l}\text { Stress } \\
\text { range at } \\
\text { mid-life } \\
(\mathrm{MPa})\end{array}$ & $\begin{array}{l}\text { Total relax: } \\
\text { at mid-life } \\
\text { Tension } \\
\text { (MPa) }\end{array}$ & $\begin{array}{l}\text { tion stress } \\
\text { Compres- } \\
\text { sion (MPa) }\end{array}$ \\
\hline CF-1 & 10 & & 1.0 & 0.786 & 1968 & 268 & -303 & 571 & 118 & \\
\hline CF-2 & & 10 & 1.0 & 0.745 & 1006 & 290 & -275 & 565 & & 137 \\
\hline CF-3 & 10 & 10 & 1.0 & 0.854 & 1142 & 263 & -272 & 535 & 118 & 128 \\
\hline CF-4 & 60 & & 1.0 & 0.788 & 1885 & 241 & -277 & 518 & 113 & \\
\hline CF-5 & & 60 & 1.0 & 0.745 & 956 & 281 & -261 & 542 & & 125 \\
\hline CF-6 & 60 & 60 & 1.0 & 0.868 & 734 & 257 & -266 & 523 & 139 & 134 \\
\hline CF-7 & 10 & & 0.5 & 0.294 & 10120 & 216 & -268 & 484 & 88 & \\
\hline CF-8 & & 10 & 0.5 & 0.297 & 2822 & 265 & -225 & 490 & & 69 \\
\hline CF-9 & 10 & 10 & 0.5 & 0.331 & 3871 & 241 & -249 & 490 & 74 & 83 \\
\hline
\end{tabular}

Table 5.6. CRIEPI Axial Creep-Fatigue Tests - Results. 
Presented in Fig. 5.5 is a mid-life cyclic stress relaxation curve obtained in a test characterized by a $1 \%$ strain range and a $1 \mathrm{~h}$ tensile hold time. Experimental results in Fig. 5.5 are shown together with predictions produced by the creep law coupled with the classical strain hardening theory (SHT) with initial stress. Although this method predicts relaxation behavior of cyclic hardening materials like 304 stainless steel fairly well [2], relaxation for the present material was significantly underpredicted. Also included in Fig. 5.5 is the prediction produced by the method proposed by Aoto et al [3] for cyclic softening materials. Aoto et al employ a creep strain equation and the SHT with initial stress taken from the first cycle to predict relaxation during the first cycle.

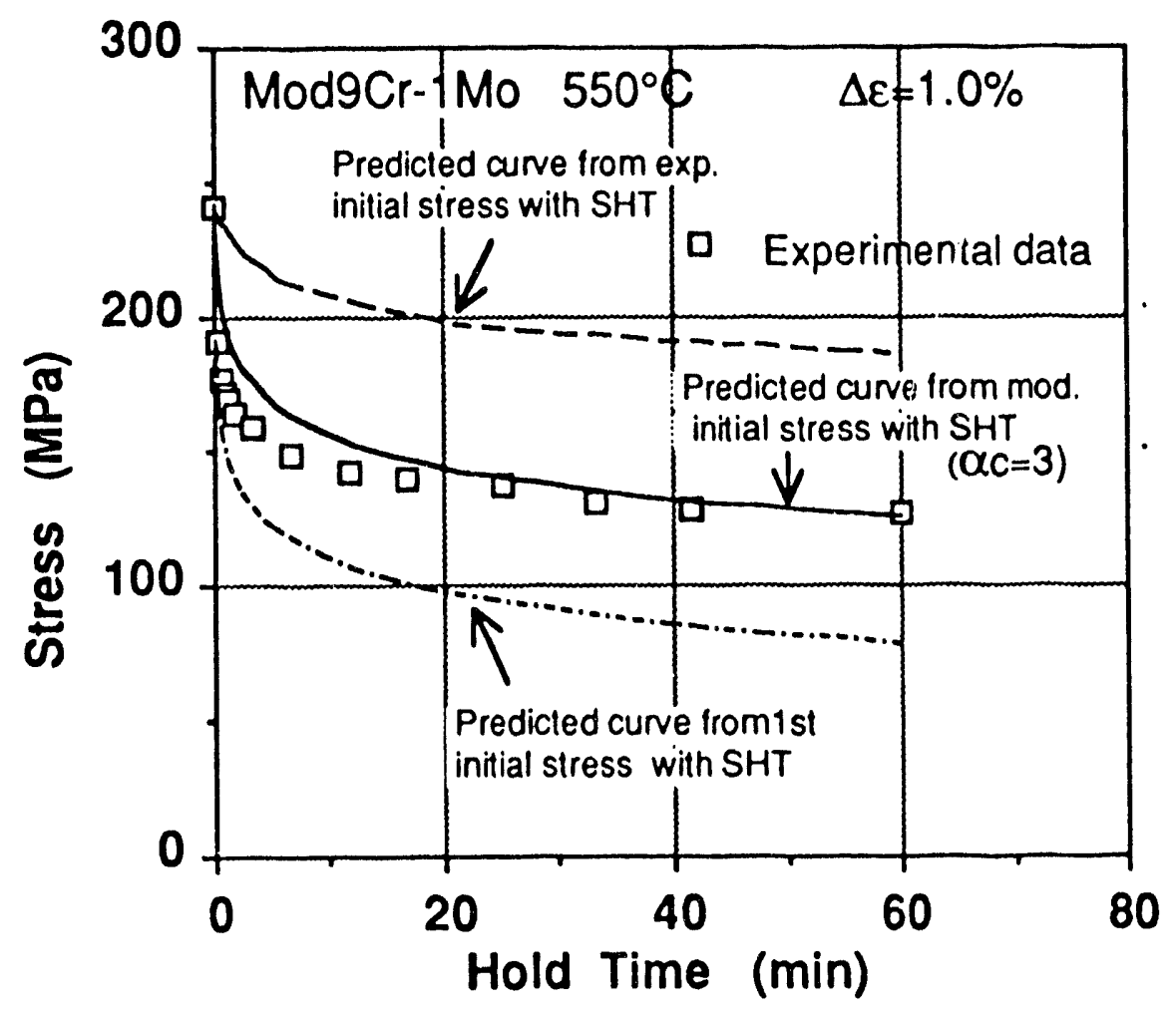

Fig. 5.5. Cyclic Relaxation Curve. Experimental Results and Model Predictions. 
Conversely, initial stress from the cycle of interest (mid-life) rather than the initial stress from the first cycle is used to predict mid-life relaxation. This method, however, overpredicted the relaxation and is therefore unsuitable for the present material. Recently Kawasaki et al [4] suggested that the initial stress from the first cycle multiplied by 0.85 be used to predict relaxation for modified $9 \mathrm{Cr}-1 \mathrm{Mo}$ steel, and demonstrated good agreement between predicted and experimental results. The relaxation curve produced by the Kawasaki method is plotted as a solid line in Fig. 5.5. Among the three predictions the latter comes closest to experiment.

Inelastic strain range vs number of cycles to failure for tests with and without the hold time is plotted in Fig. 5.6.

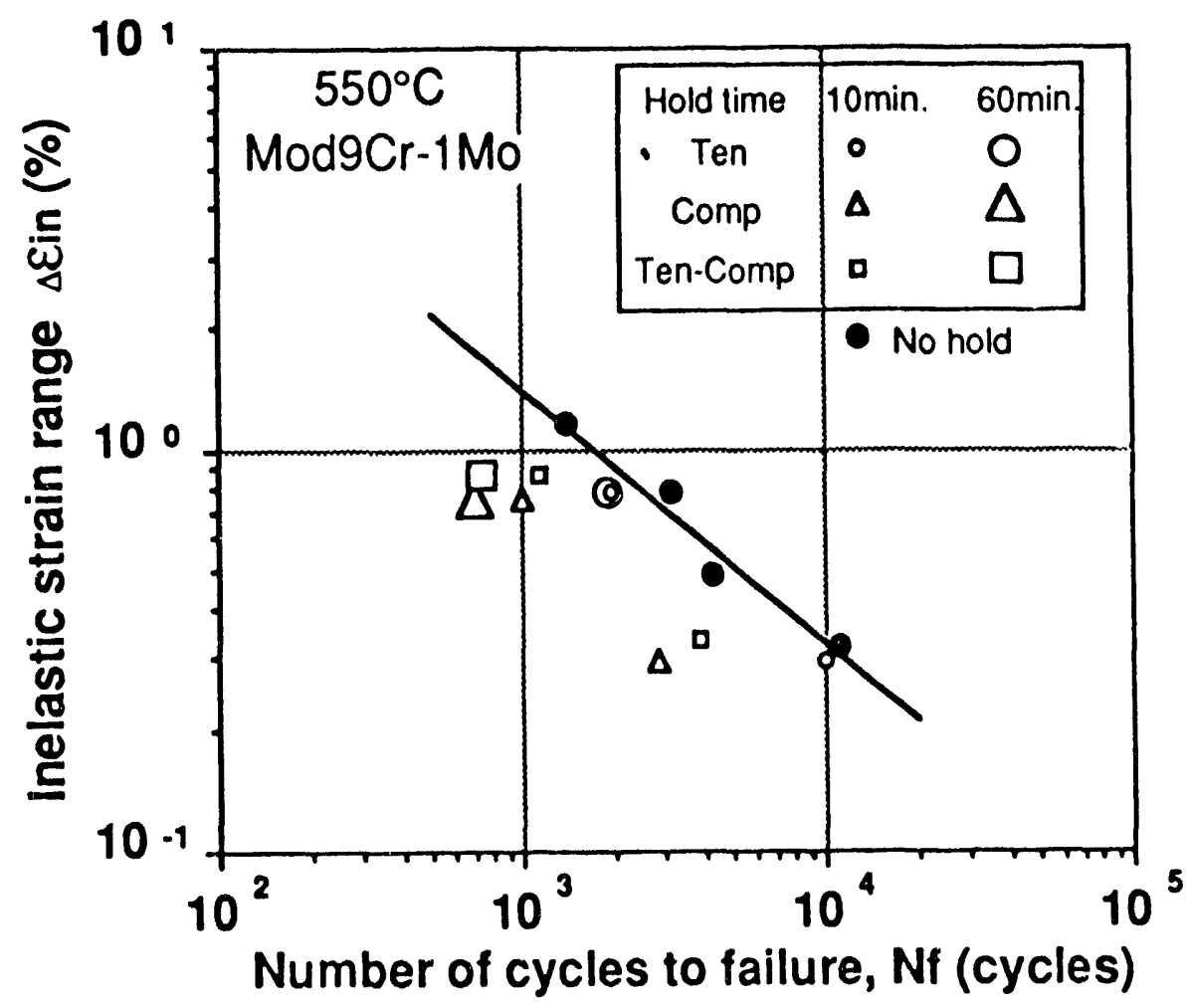

Fig. 5.6. Inelastic Strain Range vs the Number of Cycles to Failure, Tests With and Without Hold Times. 
To assess the effect of hold time on fatigue life, the number of cycles to failure was plotted vs the hold time (see Fig. 5.7).

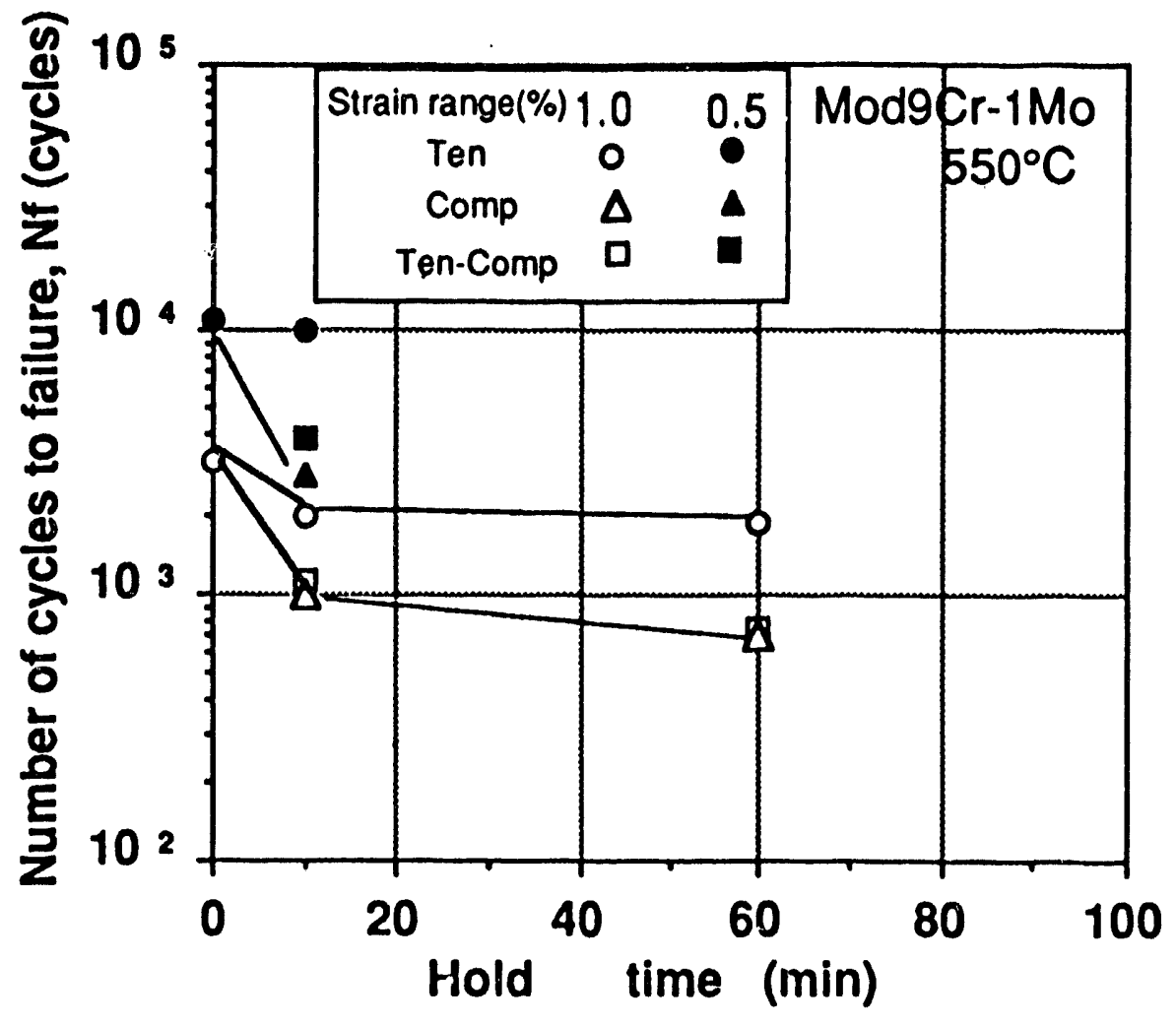

Fig. 5.7. Number of Cycles to Failure vs the Hold Time.

It is seen that tensile hold times of up to $1 \mathrm{~h}$ slightly reduced fatigue life. On the other hand, compressive and tensile-compressive hold times of only $10 \mathrm{~min}$ had considerable effect on fatigue life. Similar observations were reported for the earlier creep-fatigue tests on modified $9 \mathrm{Cr}-1 \mathrm{Mo}$ steel conducted at CRIEPI [5]. All failed specimens were studied under an optical microscope. Fracture surfaces of the specimens subjected to tests with no hold times showed no oxide layer; sharp transgranular cracks propagating from the outer surface of the specimens towards the center were observed. For the creep- 
fatigue specimens, on the other hand, both fracture surfaces and cracks initiating at the specimen surface displayed considerable oxidation. Cracks in specimens subjected to tests with tensile hold times were blunt compared to those in specimens subjected to tests with compressive hold times. This can be explained by tensile hold times causing a gradual increase in crack opening displacement, which in turn allowed oxidation between crack surfaces to take place during tensile hold time. Unless a large amount of creep damage is accumulated during the tensile hold time, the effect of oxidation on crack growth rate appears to be fairly small. The SEM micrographs obtained for the specimen subjected to a test with $1 \mathrm{~h}$ tensile hold time are presented in Fig. 5.8. While clear striations are observed in Fig. 5.8a, no cavities are seen. Thus the creep effect on failure is considered to be small even for a $1 \mathrm{~h}$ tensile hold time. Shown in Fig. $5.8 \mathrm{~b}$ is the fracture surface of the specimen subjected to a test with a $1 \mathrm{~h}$ compressive hcld time. The fracture surface in Fig. $5.8 \mathrm{~b}$ is covered with a thick oxide layer. In addition small cavities filled with oxides can be seen ahead of the crack tip. It appears that, even under compressive load, a tensile stress field has formed at the crack tip. It is reasonable to assume that the oxide layer served as a wedge between the two crack surfaces. The oxide wedge may have induced damage at the crack tip, thus making the crack growth rate in a test with compressive hold time greater than that in a test without hold time. Additional tests should be conducted to investigate the effect of other factors (for example mean stress and acceleration of crack initiation due to oxidation or compressive creep) on fatigue life with compressive hold times. 


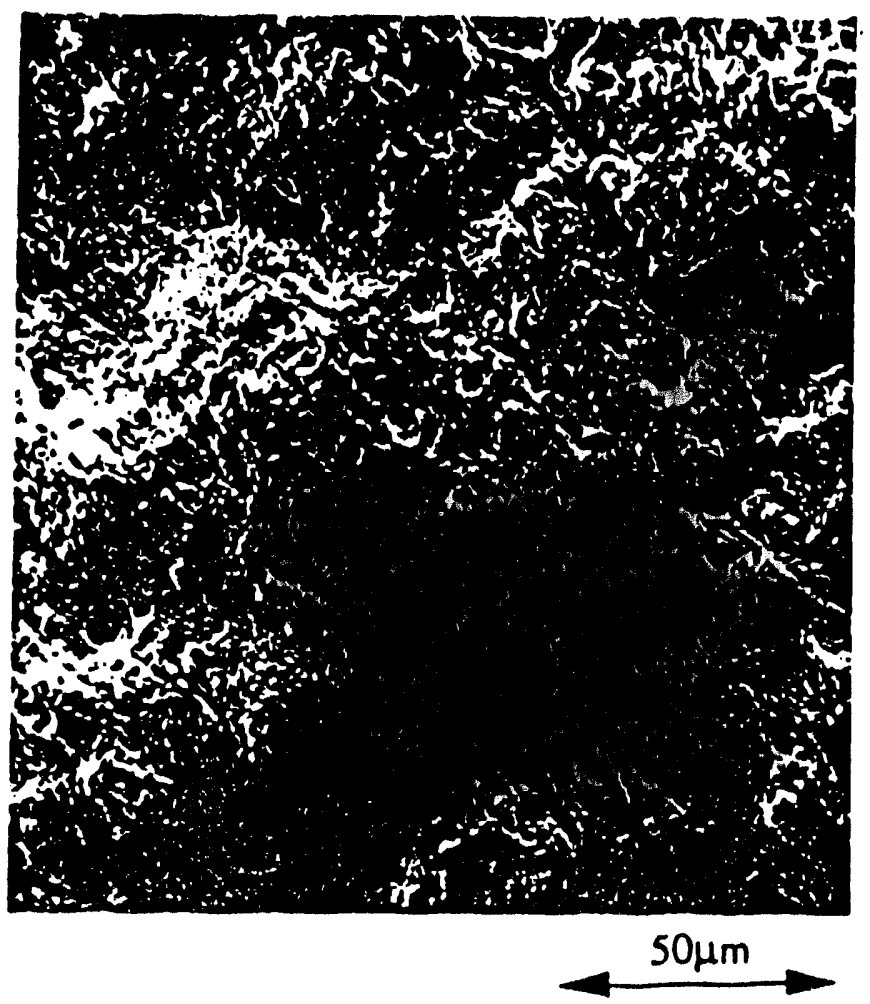

Fig. 5.8a. SEM Micrograph of the l'racture Surface of the Specimen Subjected to Creep-Fatigue Tests with $1 \mathrm{~h}$ Tensile Hold Time. 


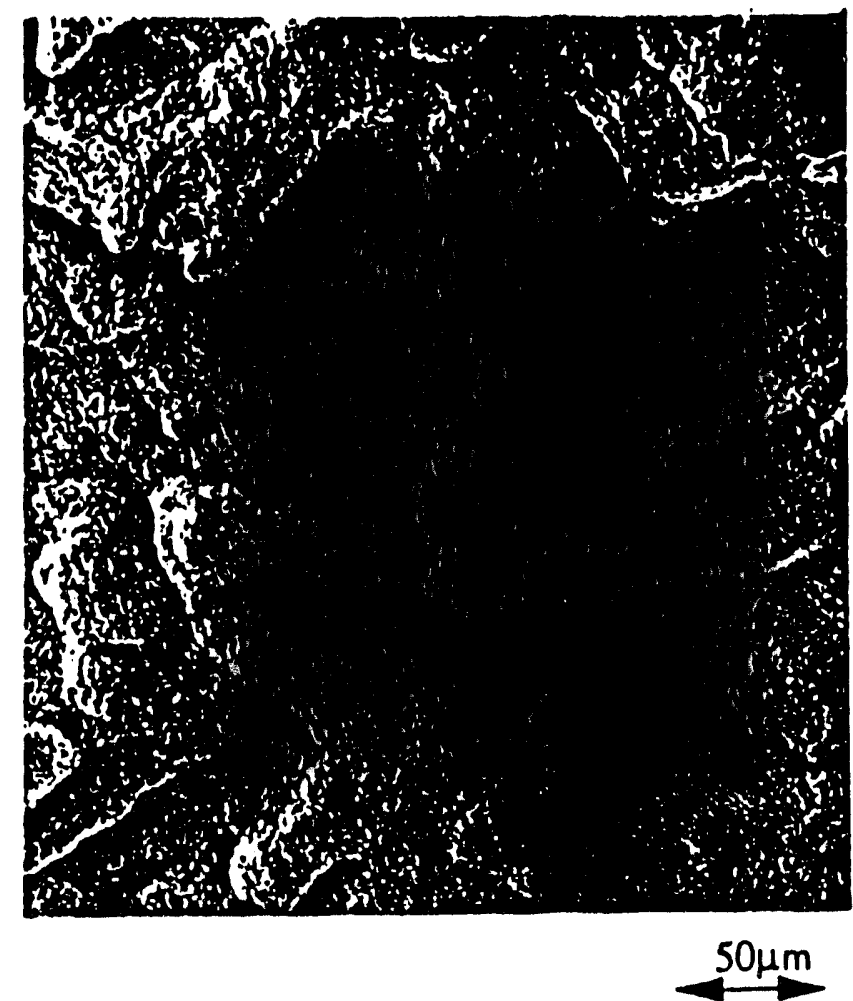

Fig. 5.8b. SEM Micrograph of the Fracture Surface of the Specimen Subjected to Creep-Fatigue Tests with $1 \mathrm{~h}$ Compressive Hold Time. 


\section{CONSTANT STRESS CREEP TESTS}

\section{EPRI}

All tests were performed at $550^{\circ} \mathrm{C}$ in an air environment. Conventional creep machines together with clamshell furnaces were employed for elevated temperature testing. Ten thermocouples were placed on the gage section of each specimen for temperature monitoring and control. For the duration of the tests, the temperature in the gage section remained uniform, and stayed within $\pm 5^{\circ} \mathrm{C}$ of the nominal temperature. Thin-walled tubular test specimens were machined to the specifications in Fig. 6.1. Test conditions and test results a:e given in Table 6.1.

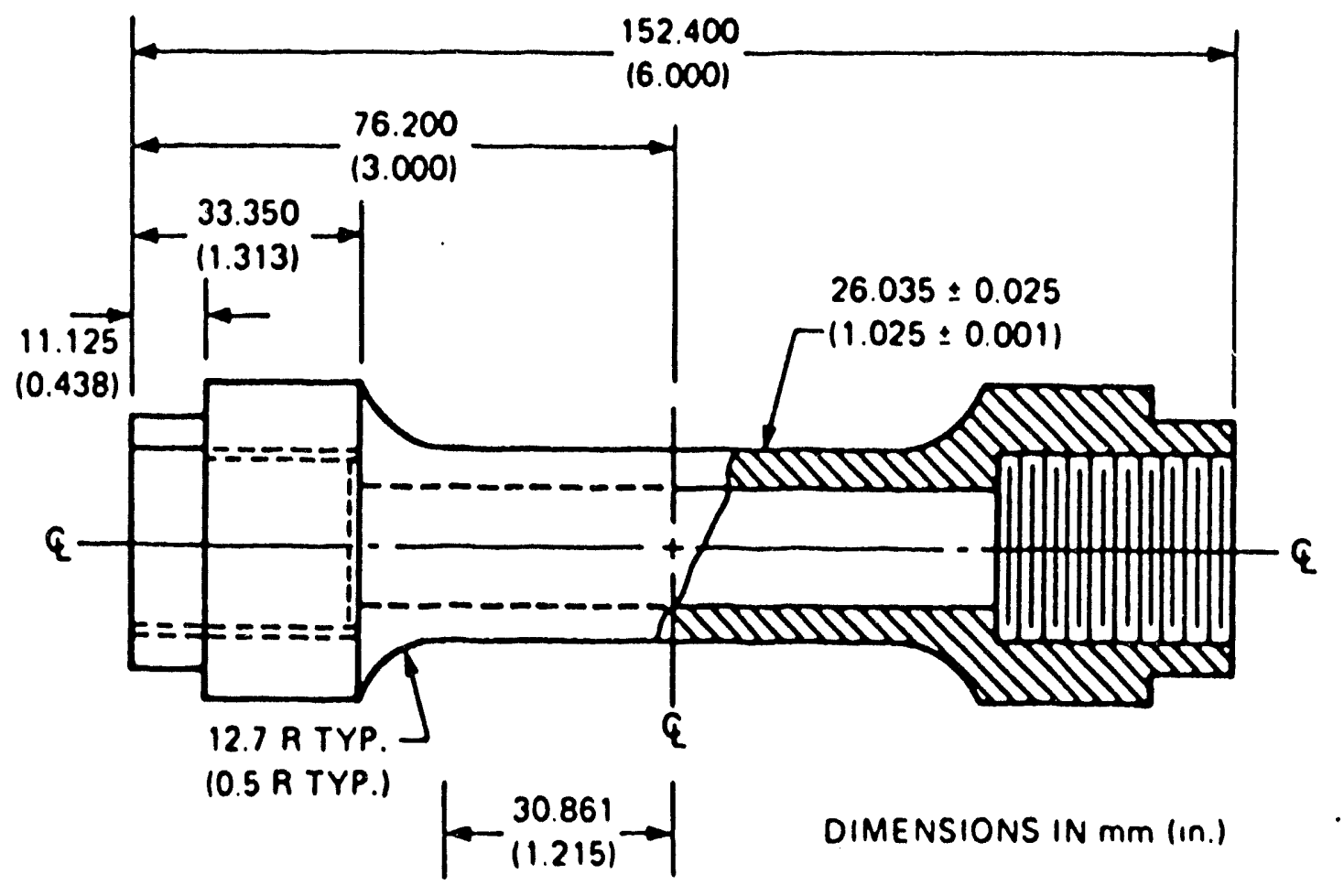

Fig. 6.1. EPRI/ORNL Thin-Walled Tubular Creep Specimen. 
Table 6.1. EPRI Constant Stress Creep Tests, $\mathrm{T}=550^{\circ} \mathrm{C}$.

\begin{tabular}{cccc}
\hline Specimen \# & $\begin{array}{c}\text { Axial Stress } \\
(\mathrm{MPa})\end{array}$ & $\begin{array}{c}\text { Shear Stress } \\
(\mathrm{MPa})\end{array}$ & $\begin{array}{c}\text { Time to Rupture } \\
(\mathrm{h})\end{array}$ \\
\hline 1 & 230 & - & 2,112 \\
2 & 240 & - & 672 \\
3 & 260 & - & 224 \\
4 & & & \\
5 & - & 133 & 4,757 \\
6 & - & 139 & 970 \\
7 & - & 150 & 230 \\
8 & 163 & 94 & 2,500 \\
9 & 170 & 98 & 601 \\
\hline
\end{tabular}

\section{CRIEPI}

The conditions for uniaxial constant stress creep tests are shown in Table 6.2.

Table 6.2. CRIEPI Uniaxial Creep Tests at $550^{\circ} \mathrm{C}$ - Test Conditions.

\begin{tabular}{|c|c|}
\hline STRESS (MPa) & \\
\hline 320 & \\
\hline 280 & \\
\hline 240 & \\
\hline 220 & \\
\hline 200 & \\
\hline 180 & \\
\hline
\end{tabular}


A single lever type creep testing machine was employed, standard tensile specimens were tested. Results are summarized in Table 6.3.

Table 6.3. CRIEPI Uniaxial Creep Tests at $550^{\circ} \mathrm{C}$ - Results.

\begin{tabular}{|c|c|c|c|c|c|}
\hline TP No. & $\begin{array}{c}\text { Stress } \\
(\mathrm{MPa})\end{array}$ & $\begin{array}{c}\text { Rupture } \\
\text { Time } \\
\text { (hour) }\end{array}$ & $\begin{array}{c}\text { Minimum } \\
\text { Creep Rate } \\
(1 / \mathrm{h})\end{array}$ & $\begin{array}{c}\text { Elongation } \\
(\%)\end{array}$ & $\begin{array}{c}\text { Reduction } \\
\text { of area } \\
(\%)\end{array}$ \\
\hline C-1 & 320 & 2 & $2.63 \times 10^{-2}$ & 32.0 & 85.3 \\
\hline C-2 & 280 & 14 & $3.66 \times 10^{-3}$ & 29.6 & 87.1 \\
\hline C-3 & 240 & 165 & $2.67 \times 10^{-4}$ & 26.3 & 86.5 \\
\hline C-4 & 220 & 384 & $9.35 \times 10^{-5}$ & 21.7 & 88.7 \\
\hline C-5 & 200 & 3940 & $8.18 \times 10^{-6}$ & 21.4 & 87.6 \\
\hline C-6 & 180 & 13077 & $1.03 \times 10^{-6}$ & 23.4 & 90.9 \\
\hline
\end{tabular}

Creep strains obtained at low stress levels are plotted vs time in Fig. 6.2 together with the creep curves produced by a creep equation reported by Kawasaki et al [4].

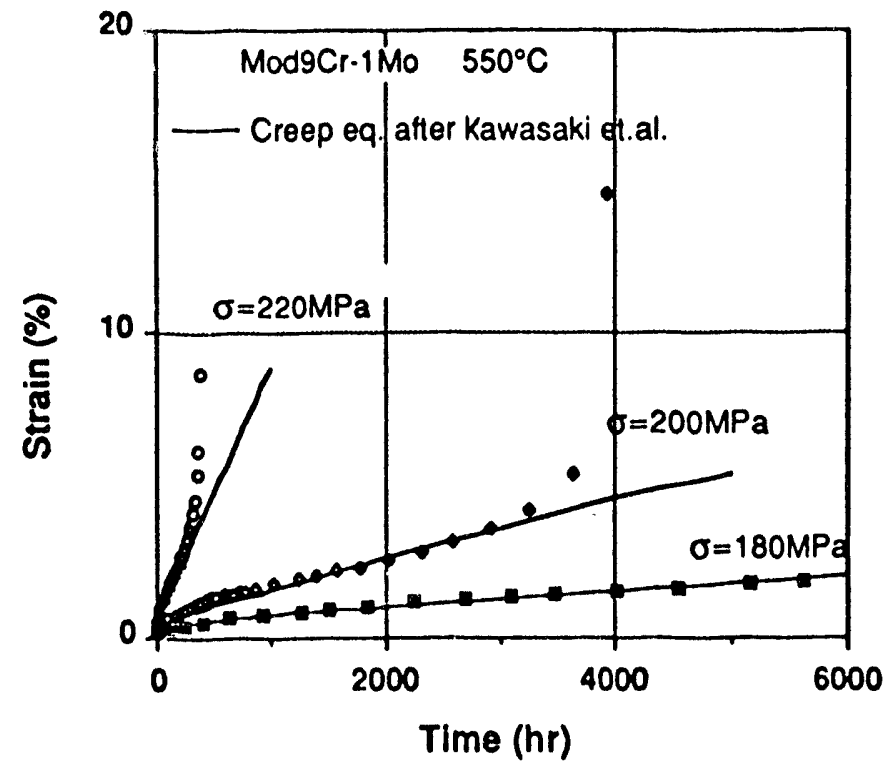

Fig. 6.2. Creep Curves, Experiment and Predictions. 
Creep-strain and creep-rupture equations are given in Table 6.4.

Table 6.4. Creep Strain and Rupture Equations.

Creep Strain Equation

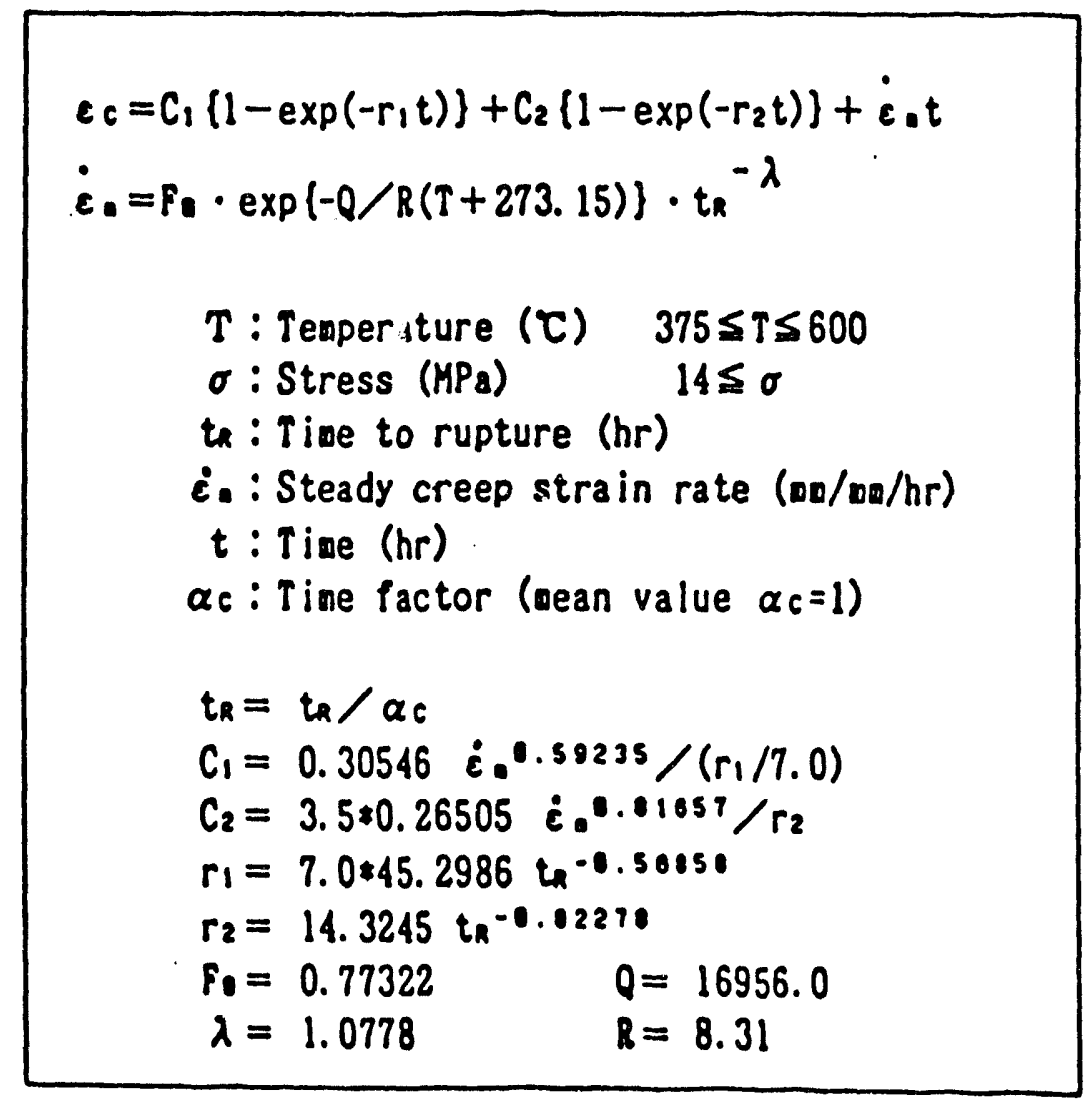

Creep Rupture Equation

$$
\begin{aligned}
& (T+273.15)\left\{\left(\log _{1} \cdot\left(\alpha_{R} \cdot t_{R}\right)+C\right)=\right. \\
& A_{0}+A_{1} \log _{10}(\sigma / 8)+A_{2}\left(\log _{1} \theta(\sigma / 8)\right)^{2} \\
& T \text { : Temperature }(\tau) \quad 375 \leq \tau \leq 700 \\
& \sigma: \text { Stress (MPa) } 35 \leqq \sigma \\
& \text { to: Tire to rupture (hr) } \\
& \left.8 \text { : sravity (m/ } \mathrm{sec}^{2}\right) \\
& \alpha_{R}: T \text { ine factor (nean value } \alpha_{R}=1 \text { ) } \\
& C=29.1146 \quad \Lambda_{1}=3055.52 \\
& A_{1}=31808.82 \quad A_{2}=-5148.248
\end{aligned}
$$


Transient and steady-state creep is predicted fairly well. Creeprupture data are presented in Fig. 6.3 together with the creep-rupture curve obtained from the creep equations in Table 6.4.

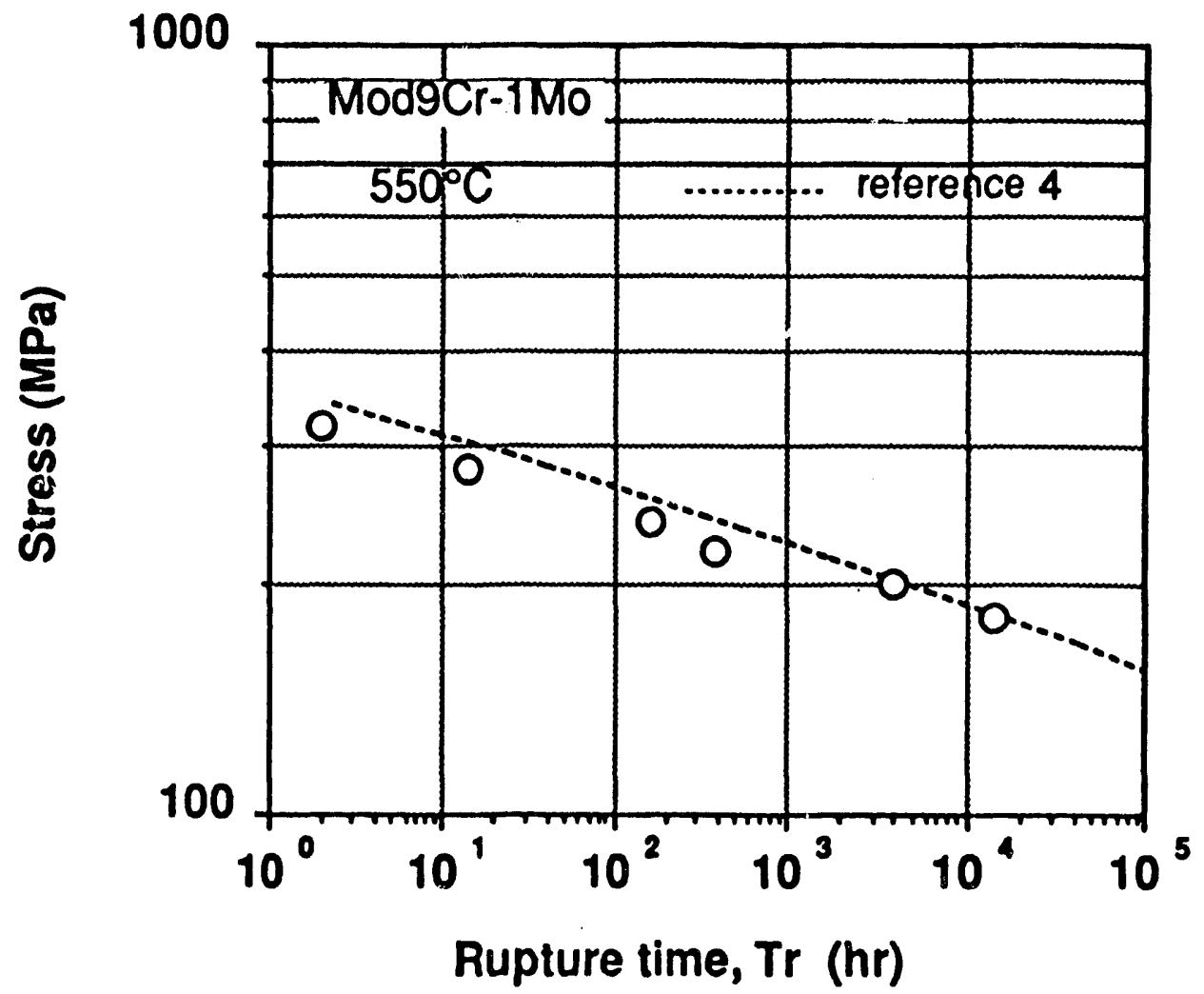

Fig. 6.3. Creep-Rupture Curve.

It is seen that the creep-rupture equations predict experimental results fairly well. Elongation and reduction in area at the moment of rupture (see Fig. 6.4) remain virtually unchanged until rupture time reaches $4000 \mathrm{~h}$. The relation between minimum creep rate and rupture time is presented in Fig. 6.5, which agrees well with reference [3]. The Monkman-Grant relation for this material can be written as follows:

$$
\dot{\varepsilon}_{8} t_{r}^{-1.08}=0.0648
$$




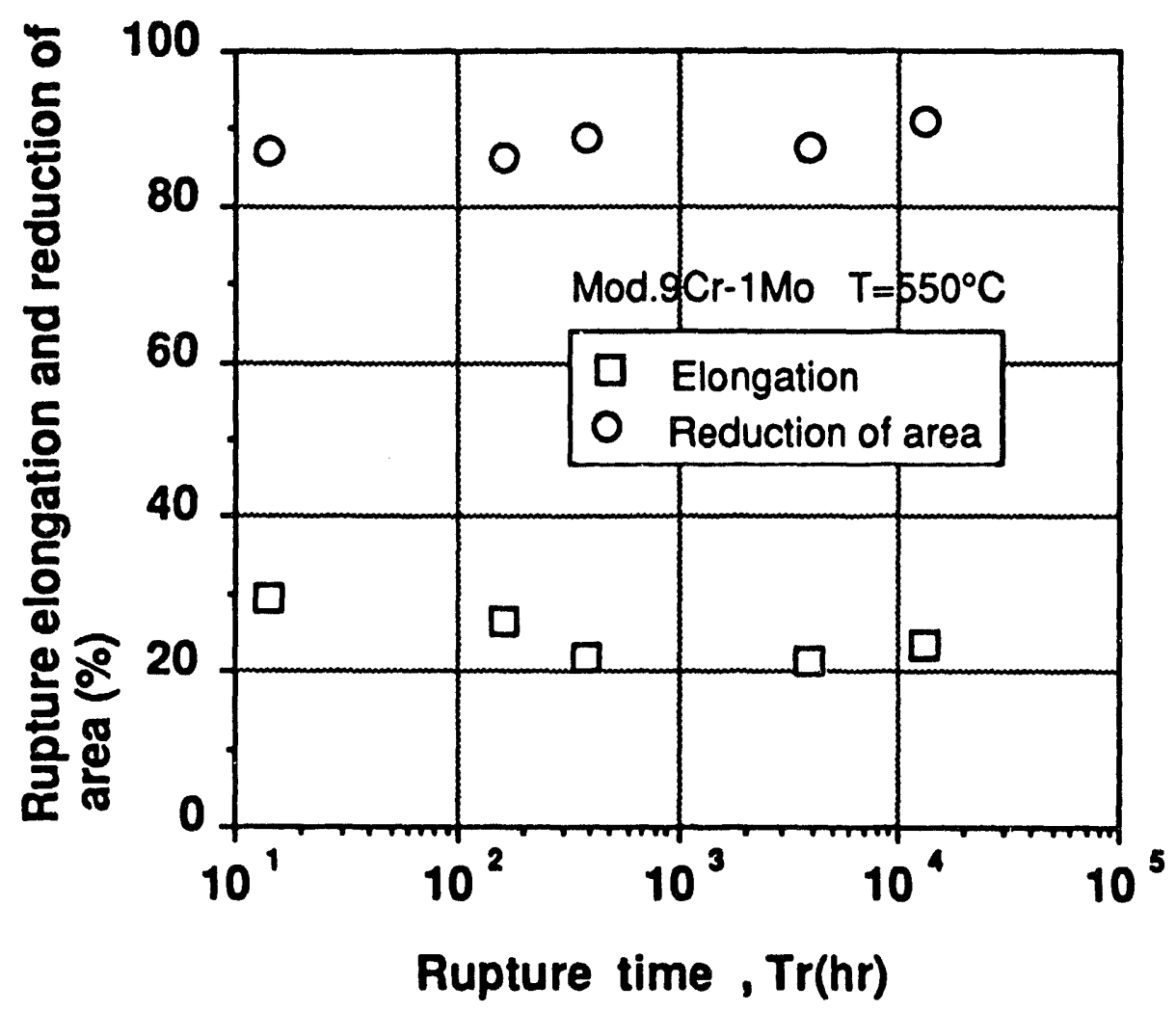

Fig. 6.4. Creep-Rupture Ductility vs Rupture Time.

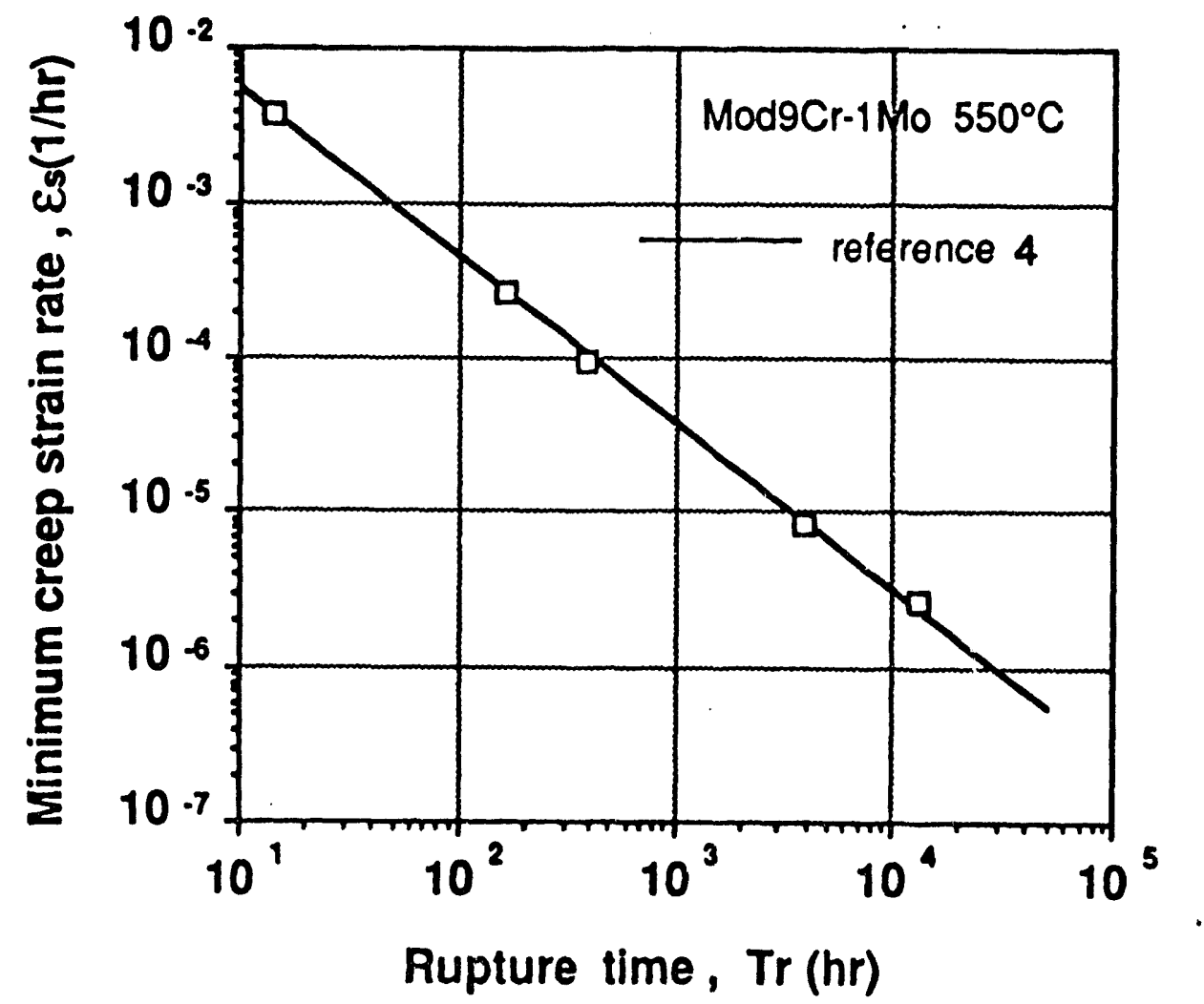

Fig. 6.5. Minimum Creep Rate vs Rupture Time. 


\section{BIAXIAL FATIGUE AND CREEP-FATIGUE TESTS}

\subsection{LOW CYCLE FATIGUE TESTS}

A series of thirteen biaxial strain controlled cyclic tensiontorsion tests have been performed at $550^{\circ} \mathrm{C}$ (see Table 7.1) in CRIEPI. Thin-walled cylindrical specimens were machined to the specifications in Fig. 7.1. A servo-electro-hydraulic axial-torsional testing machine and a high frequency induction heating system were used. The temperature distribution over the gage length of $12.5 \mathrm{~mm}$ was within $\pm 3^{\circ} \mathrm{C}$ of the nominal temperature. Axial and shear strains were simultaneously and independently measured by a high temperature biaxial strain transducer.

The strain ratio, $\varphi$, was defined as the ratio of applied shear strain range $\Delta \gamma$ to applied axial strain range $\Delta \varepsilon$. Tension-compression $(\varphi=0)$, pure torsion $(\varphi=\infty)$, and combined tension-torsion in-phase $(\varphi=1.73)$ tests were conducted. A triangular waveform and a von Mises equivalent strain rate of $10^{-3} \mathrm{~s}^{-1}$ were used. The Mises equivalent strain ranges, $\Delta \varepsilon_{M}$, were $0.5,1.0$, and $1.4 \%$. The $90^{\circ}$ out-of-phase tension-torsion tests employed sinusoidal waveform, the Mises equivalent strain ranges were $0.5,0.7,1.0$, and $1.4 \%$.

Tabie 7.1. CRIEPI Biaxial Fatigue Tests - Test Conditions.

$\overline{\Delta \varepsilon_{m}}=0.1 \% /$ sec $\quad T=550^{\circ} \mathrm{C}$
In-Phase (phase angle $=0^{\circ}$ )
\begin{tabular}{|c|c|c|c|}
\hline $\overrightarrow{E m}(\%)$ & 0 & 1.73 & $\infty$ \\
\hline 1.4 & 0 & & 0 \\
\hline 1.0 & 0 & 0 & 0 \\
\hline 0.5 & 0 & 0 & 0 \\
\hline
\end{tabular}

$$
\varphi=\Delta \gamma / \Delta \varepsilon
$$

Out-of-Phase (phase angle $=90^{\circ}$ )

\begin{tabular}{|c|c|}
\hline \multicolumn{1}{|c|}{$\varphi$} & 1.73 \\
\hline 1.4 & 0 \\
\hline 1.0 & \\
\hline 0.7 & 0 \\
\hline 0.5 & 0 \\
\hline
\end{tabular}


168
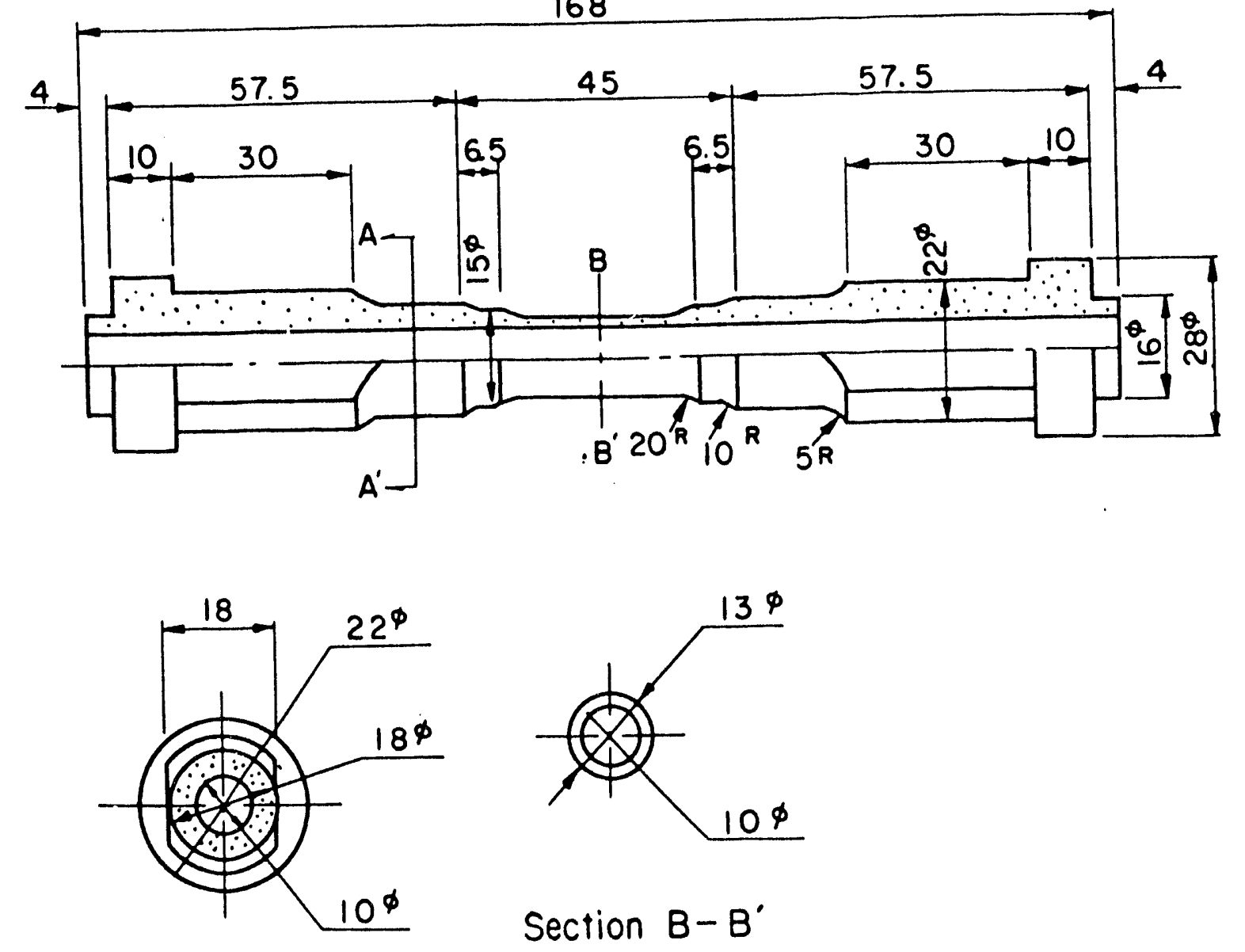

Section $B-B^{\prime}$

Direction $A-A^{\prime}$

Fig. 7.1. CRIEPI Thin-Walled Tubular Specimen.

Test results are summarized in Table 7.2. Results of the present study together with those obtained at CRIEPI earlier [5] are also presented in Fig. 7.2, where biaxial low cycle fatigue life is correlated with $\Delta \varepsilon_{M}$.

Fatigue life appears to be significantly influenced by the strain ratio; the shortest life for the in-phase tests was observed for $\varphi=0$. The $90^{\circ}$ out-of-phase tests produce shorter fatigue lives than the in-phase 


\begin{tabular}{|c|c|c|c|c|c|c|c|c|}
\hline TP No. & $\begin{array}{l}\text { Loading } \\
\text { mode }\end{array}$ & $\begin{array}{l}\text { Strain } \\
\text { ratio } \\
\varphi\end{array}$ & \begin{tabular}{|l|}
$\begin{array}{l}\text { Mises } \\
\text { equivalent } \\
\text { strain range } \\
\Delta \varepsilon m\end{array}(\%)$ \\
\end{tabular} & \begin{tabular}{|c|} 
Axial strain \\
range \\
$\Delta E$ \\
$(\%)$ \\
\end{tabular} & \begin{tabular}{|c|} 
Torsional \\
strain range \\
$\Delta \gamma$ \\
$(\%)$ \\
\end{tabular} & $\begin{array}{l}\text { Inelastic } \\
\text { axial strain } \\
\text { range } \\
\Delta \operatorname{Ein}(\%)\end{array}$ & \begin{tabular}{|l|} 
Inelastic \\
torsional \\
strain range \\
$\Delta \gamma_{\text {in }} \quad(\%)$
\end{tabular} & $\begin{array}{l}\text { Number of } \\
\text { cycles to } \\
\text { failure } \\
\text { Nt (cycles) }\end{array}$ \\
\hline BF- 1 & \multirow{9}{*}{ In-phase } & \multirow{3}{*}{0} & 1.4 & 1.4 & - & 1.08 & - & 510 \\
\hline$B F-2$ & & & 1.0 & 1.0 & - & 0.70 & - & 1120 \\
\hline BF- 3 & & & 0.5 & 0.5 & - & 0.23 & - & 4220 \\
\hline BF- 4 & & \multirow{3}{*}{1.73} & 1.4 & 0.99 & 1.71 & 0.76 & 1.37 & 860 \\
\hline BF- 5 & & & 1.0 & 0.71 & 1.23 & 0.48 & 0.86 & 1730 \\
\hline BF- 6 & & & 0.5 & 0.35 & 0.61 & 0.16 & 0.31 & 5960 \\
\hline BF- 7 & & \multirow{3}{*}{$\infty$} & 1.4 & - & 2.43 & - & 1.86 & 970 \\
\hline BF- 8 & & & 1.0 & - & 1.73 & - & 1.17 & 2800 \\
\hline BF- 9 & & & 0.5 & - & 0.87 & - & 0.36 & 10900 \\
\hline$B F-10$ & \multirow{4}{*}{$\begin{array}{l}\text { Out-of- } \\
\text { phase }\end{array}$} & \multirow{4}{*}{1.73} & 1.4 & 1.4 & 2.42 & 1.21 & 2.20 & 260 \\
\hline$B F-11$ & & & 1.0 & 1.0 & 1.73 & 0.84 & 1.49 & 510 \\
\hline BF-12 & & & 0.7 & 0.7 & 1.21 & 0.52 & 0.99 & 910 \\
\hline BF-13 & & & 0.5 & 0.5 & 0.87 & 0.30 & 0.52 & 2420 \\
\hline
\end{tabular}

Table 7.2. CRIEPI Biaxial Fatigue Tests - Results. 


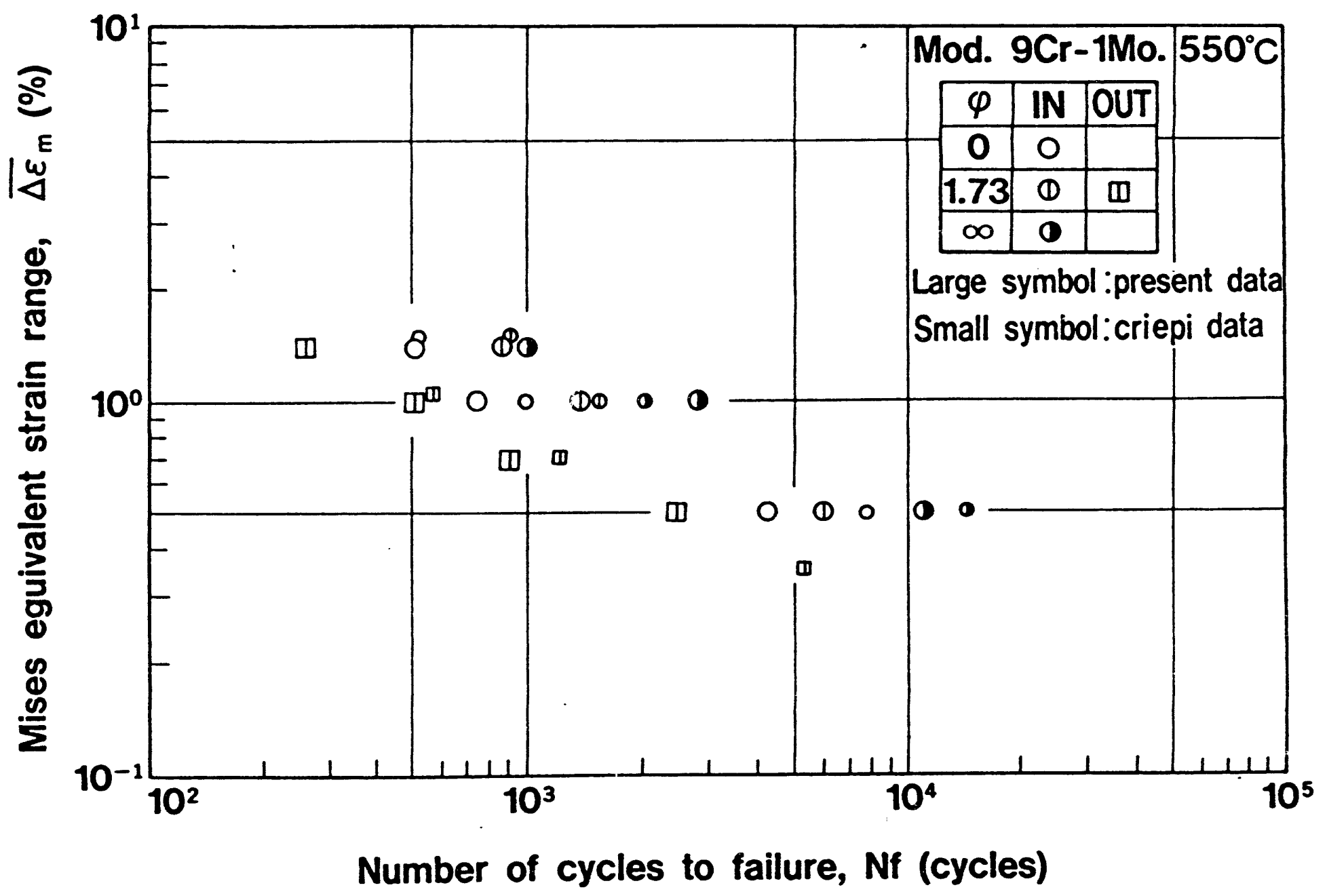

$\stackrel{A}{\omega}$

Fig. 7.2. Correlation of Biaxial Low Cycle Fatigue Life with the von Mises Equivalent Strain Range. 
tests. This indicates that fatigue life estimates for components subjected to $90^{\circ}$ out-of-phase loading that are based on uniaxial fatigue data will not be conservative.

Ogata et al $[6,7]$ proposed the equivalent shear strain range, $\overline{\Delta \gamma}$, as a parameter for evaluating biaxial low cycle fatigue life under inphase and out-of-phase loading for type 304 stainless steel. Below, an attempt is made to define $\overline{\Delta \gamma}$ for modified $9 \mathrm{Cr}-1 \mathrm{Mo}$ steel and to correlate biaxial fatigue life with $\overline{\Delta y}$. The definition of $\overline{\Delta y}$ is based on iso- $N_{f}$ life contours on the modified $\Gamma$-plane, a plot with the maximum shear strain range, $\Delta \gamma_{\max } / 2$, on the $x$-axis and normal strain range, $\Delta \varepsilon n$, measured on the $\Delta \gamma_{\max } / 2$-plane, on the $y$-axis. Iso- $N_{f}$ contours on the modified $\Gamma$-plane are shown in Fig. 7.3 for both inphase and out-of-phase tests. The iso- $\mathrm{N}_{\mathrm{f}}$ contours obtained for outof-phase tests on type 304 stainless steel [6,7] appear as straight lines. In general iso- $N_{f}$ contours can be described by the following equation:

$$
\left(\frac{\Delta \gamma_{\max } / 2}{g}\right)^{\prime}+\left(\frac{\Delta \varepsilon_{n}}{h}\right)^{\prime}=1
$$

where $\mathrm{g}, \mathrm{h}$ and $\mathrm{j}$ are material constants. From Eq. (7.2), $\overline{\Delta \gamma}$ can be defined as:

$$
\overline{\Delta \gamma}=\left\{\left(\Delta \gamma_{\max } / 2\right)^{\prime}+A \Delta \varepsilon_{n}^{\prime}\right\}^{1 / 1}
$$

where $A$ is a material constant. From the iso- $N_{f}$ contours in Fig. 7.3, $\overline{\Delta \gamma}$ is given by:

$$
\begin{aligned}
& \overline{\Delta \gamma}=\left\{\left(\Delta \gamma_{\max } / 2\right)^{2}+1.76 \Delta \varepsilon_{n}^{2}\right\}^{1 / 2}, \quad \text { (in-phase ) } \\
& \overline{\Delta \gamma}=\Delta \gamma_{\max } / 2+0.9 \Delta \varepsilon_{\mathrm{n}}, \quad\left(90^{\circ}\right. \text { out-of-phase ) }
\end{aligned}
$$

Correlation of biaxial fatigue life with $\overline{\Delta y}$ for modified $9 \mathrm{Cr}$-1Mo steel is shown in Fig. 7.4. Biaxial fatigue life appears to be well correlated with $\overline{\Delta \gamma}$ for both in-phase and $90^{\circ}$ out-of-phase tests. 


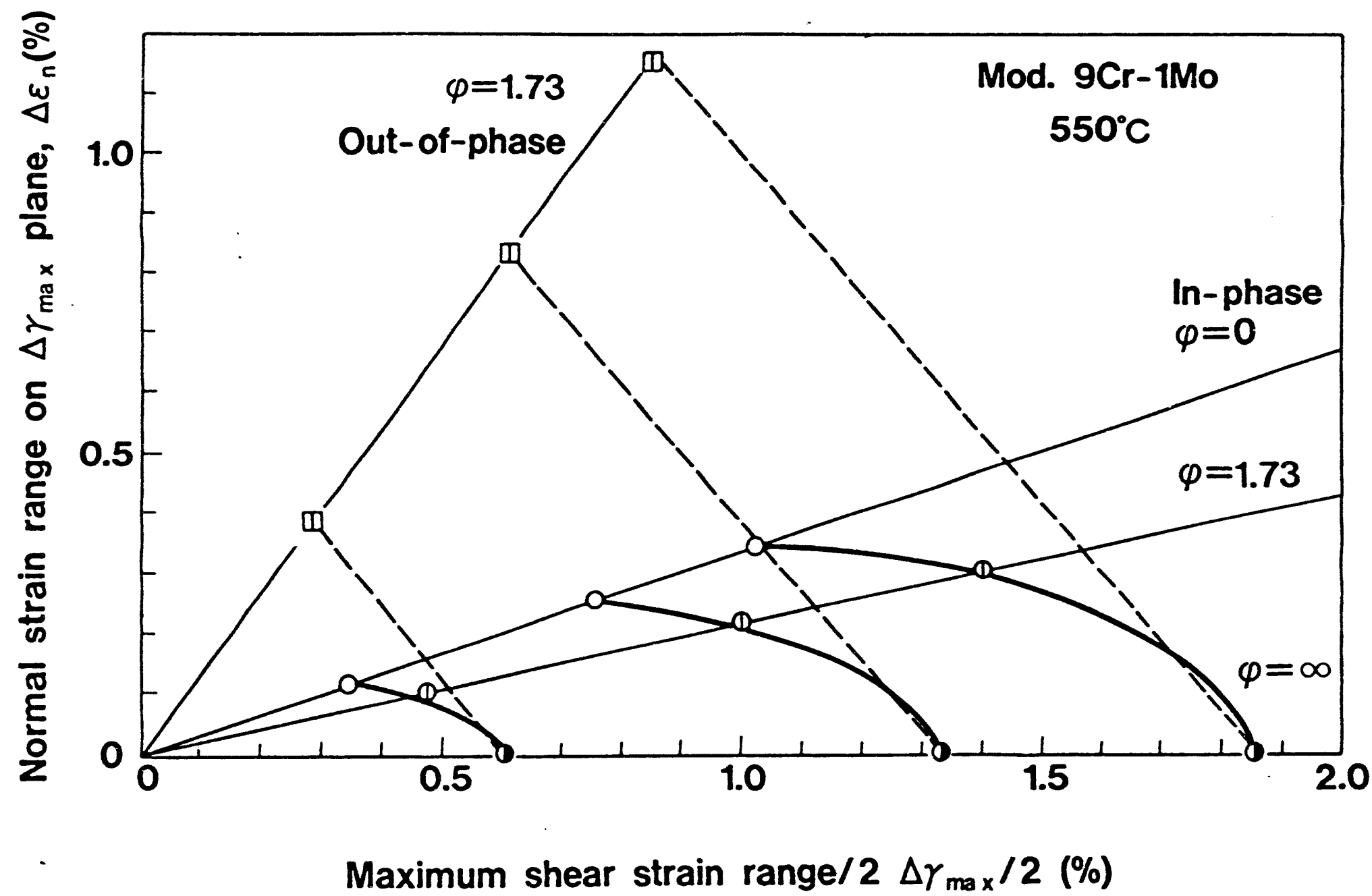

Fig. 7.3. Fatigue Life Contours on the Modified $\Gamma$ Plane. 


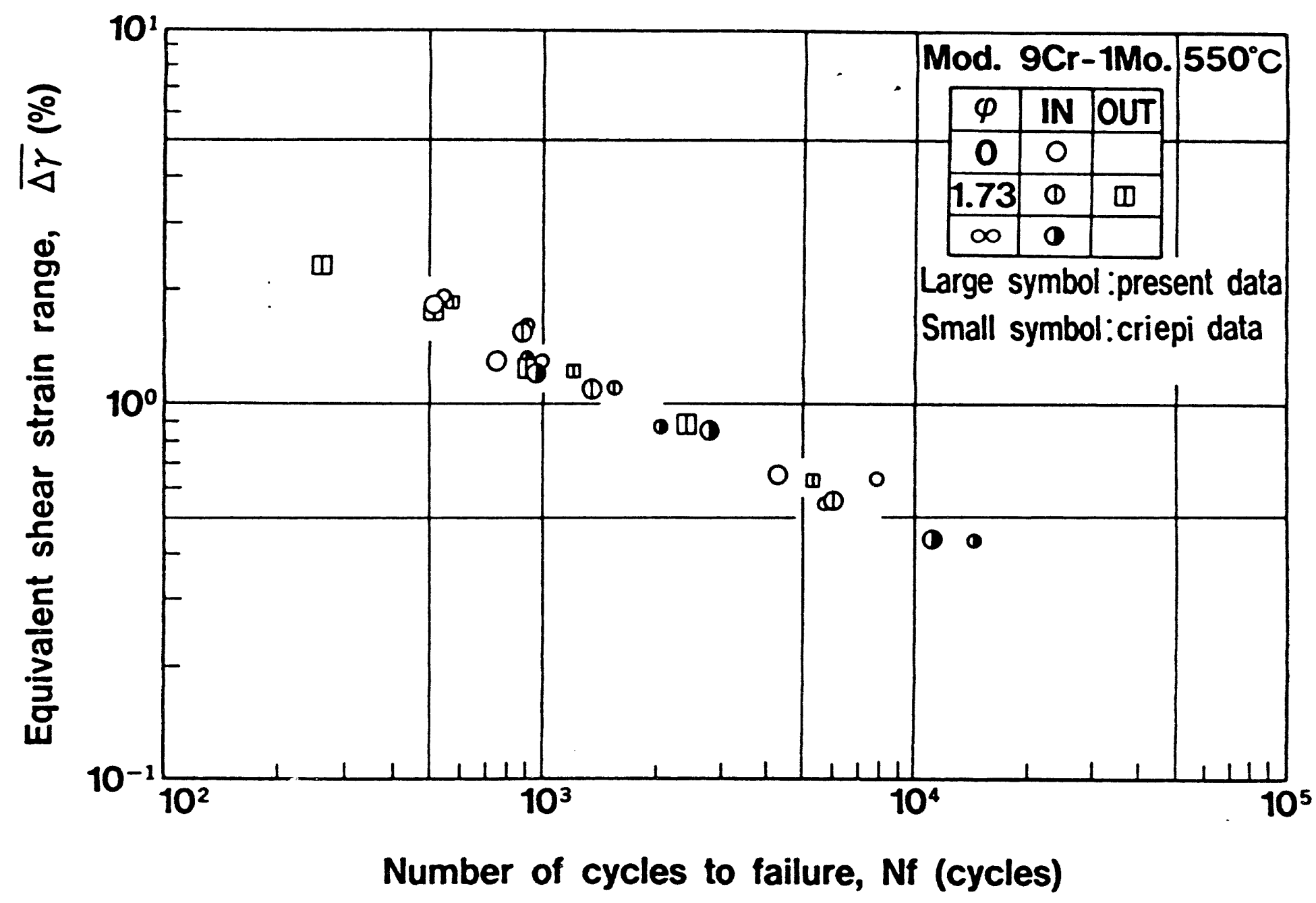

A

Fig. 7.4. Correlation of Biaxial Low Cycle Fatigue Life with the Equivalent Shear Strain Range. 


\subsection{CREEP-FATIGUE TESTS}

\section{CRIEPI}

A series of six biaxial tension-torsion creep-fatigue tests were performed at $550^{\circ} \mathrm{C}$. For all tests Mises equivalent strain rate was constant and equal to $10^{-3} \mathrm{~s}^{-1}$ and Mises equivalent strain range was $1.0 \%$. Two hold times (600 $\mathrm{s}$ and $1 \mathrm{~h}$ ) were introduced at maximum tensile strain. For each hold time the following tests were performed:

(i) $\varphi=0$;

(ii) $\varphi=1.7$, in-phase;

(iii) $\varphi=1.7,90^{\circ}$ out-of-phase.

Test results are summarized in Table 7.3. Biaxial creep-fatigue behavior of modified $9 \mathrm{Cr}-1 \mathrm{Mo}$ steel appears similar to the biaxial fatigue behavior. Fatigue life obtained in tests with $\varphi=0$ exceeds that obtained in the in-phase tests with $\varphi=1.7$. Fatigue life is significantly reduced under nonproportional loading conditions with the sarne Mises equivalent strain range. In specimens tested with $\varphi=$ 0 , cracks propagated mainly in the direction normal to the axis of the specimen, $i$. $\theta$. the mode I direction. In addition, clear striations were observed on the fracture surfaces. Conversely, for specimens tested out-of-phase with $\varphi=1.7$, main cracks propagated in the direction normal to the axis of the specimen. In this case both striations and rubbing marks were observed. As seen in Table 7.3, an increase in hold time to $1 \mathrm{~h}$ did not result in a significant decrease in fatigue life. 


\begin{tabular}{|c|c|c|c|c|c|c|c|c|c|c|c|}
\hline TP No. & $\begin{array}{l}\text { Loading } \\
\text { mode }\end{array}$ & $\begin{array}{c}\text { Strain } \\
\text { ratio } \\
\varphi\end{array}$ & $\begin{array}{l}\text { Mises } \\
\text { equivalent } \\
\text { strain range } \\
\Delta \varepsilon_{m} \quad(\%)\end{array}$ & $\begin{array}{c}\text { Axial strain } \\
\text { range } \\
\Delta E \\
(\%)\end{array}$ & $\begin{array}{c}\text { Torsional } \\
\text { strain range } \\
\Delta \gamma \\
(\%)\end{array}$ & $\begin{array}{c}\text { Inelastic } \\
\text { axial strain } \\
\text { range } \\
\Delta E \text { in } \\
(x)\end{array}$ & $\begin{array}{c}\text { Inelastic } \\
\text { torsional } \\
\text { strain range } \\
\Delta \gamma \text { in } \\
(\%)\end{array}$ & $\begin{array}{c}\text { Relaxation } \\
\text { in axial } \\
\text { stress } \\
\text { Or } \\
\text { (MPa) }\end{array}$ & $\begin{array}{c}\text { Relaxation } \\
\text { in torsional } \\
\text { stress } \\
\tau_{r} \\
\text { (MPa) }\end{array}$ & $\begin{array}{r}\text { Hold time } \\
\text { (min.) }\end{array}$ & $\begin{array}{l}\text { Number of } \\
\text { cycles to } \\
\text { failure } \\
\mathrm{Ni} \\
\text { (cycles) }\end{array}$ \\
\hline BCF-1 & \multirow{4}{*}{ In-phase } & & 1.0 & 1.0 & - & 0.714 & $\longrightarrow$ & 82.8 & $\longrightarrow$ & 10 & 1250 \\
\hline BCF-2 & & & 1.0 & 1.0 & - & 0.722 & - & 106 & - & 60 & 900 \\
\hline BCF-3 & & \multirow{2}{*}{1.73} & 1.0 & 0.71 & 1.23 & 0.502 & 0.891 & 56.2 & 38.4 & 10 & 1650 \\
\hline$B C F-4$ & & & 1.0 & 0.71 & 1.23 & 0.510 & 0.900 & 91.6 & 45.6 & 60 & 1540 \\
\hline BCF-5 & \multirow{2}{*}{$\begin{array}{l}\text { Out-of- } \\
\text { phase }\end{array}$} & \multirow{2}{*}{1.73} & 1.0 & 1.0 & 1.7 & 0.762 & 1.32 & 91.9 & 36.4 & 10 & 620 \\
\hline BCF-6 & & & 1.0 & 1.0 & 1.7 & 0.825 & 1.19 & 134 & 91.6 & 60 & 370 \\
\hline
\end{tabular}

Table 7.3. CRIEPI Biaxil Creep-Fatigue Tests - Results. 


\section{CREep-fatigue life eVAlUation}

\subsection{LIFE EVALUATION WITH EXISTING METHOD}

In this study the linear damage rule and the ductility-exhaustion method were used in creep-fatigue damage evaluation. Using the linear-damage time-fraction rule, fatigue damage, $D_{1}$, and creep damage, $D_{c}$, are calculated as:

$$
\begin{gathered}
D_{1}=\frac{N_{1}}{N_{10}} \\
D_{c}=N_{1}\left(\int_{0}^{n} \frac{d t}{t_{1}}\right)
\end{gathered}
$$

where $N_{1}$ and $N_{10}$ are numbers of cycles to failure for a given strain range with and without hold times, respectively, th is the hold time, and $t_{r}$ is the creep-rupture time. Using the creep-fatigue damage factor $D$ as a failure criterion, creep-fatigue life is estimated as

$$
D_{1}+D_{c}=D
$$

Fatigue and creep damage in creep-fatigue tests are plotted on the $D_{f}$ $D_{c}$ diagram in Fig. 8.1. Creep damage calculations were based on experimental mid-life relaxation curves and the creep-rupture properties shown in Table 6.4. The absolute value of stress was used to calculate the creep damage during compressive hold time. It is seen in Fig. 8.1 that the values of $D_{c}$ are very small, thus the creep-fatigue life cannot be estimated with $D=1$. Similar values of $D_{c}$ were reported and an alternative method was proposed for creep damage calculations by Koto et al [8], where $0.1 t_{r}$ was used instead of $t_{r}$. This consideration was based on the fact that due to cyclic softening creep rupture strength is reduced to 0.1 of it original value. The values of $D_{f}$ calculated with $0.1 t_{r}$ are shown on the $D_{f}-D_{c}$ diagram in Fig. 8.2. 


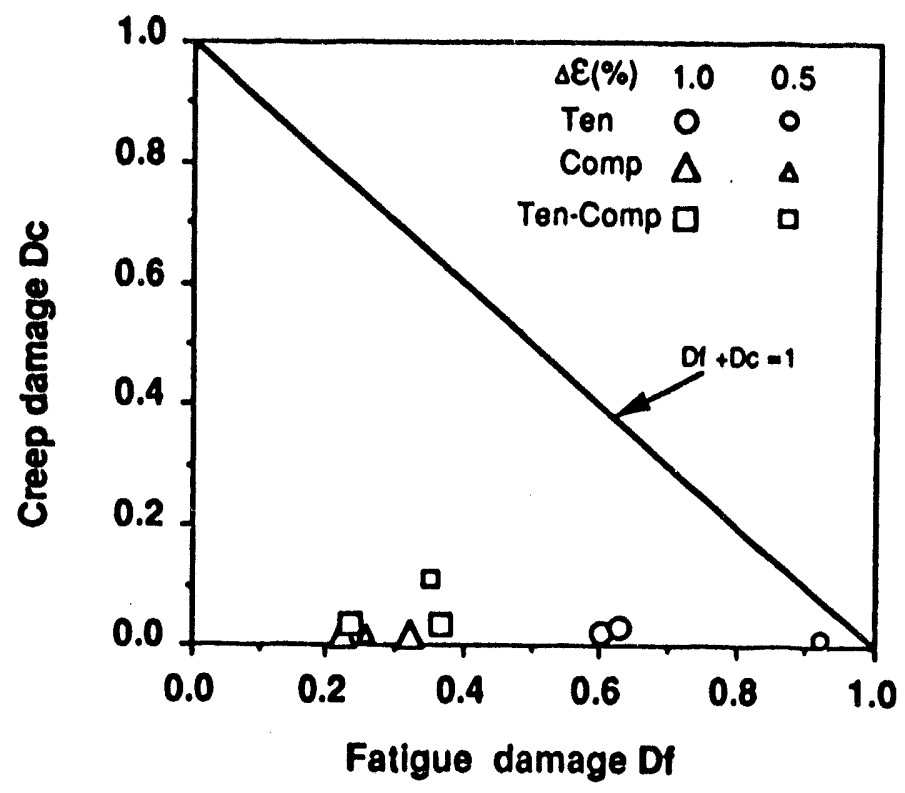

Fig. 8.1. Fatigue and Creep Damage Diagram Based on the Conventional Time Fraction Rule.

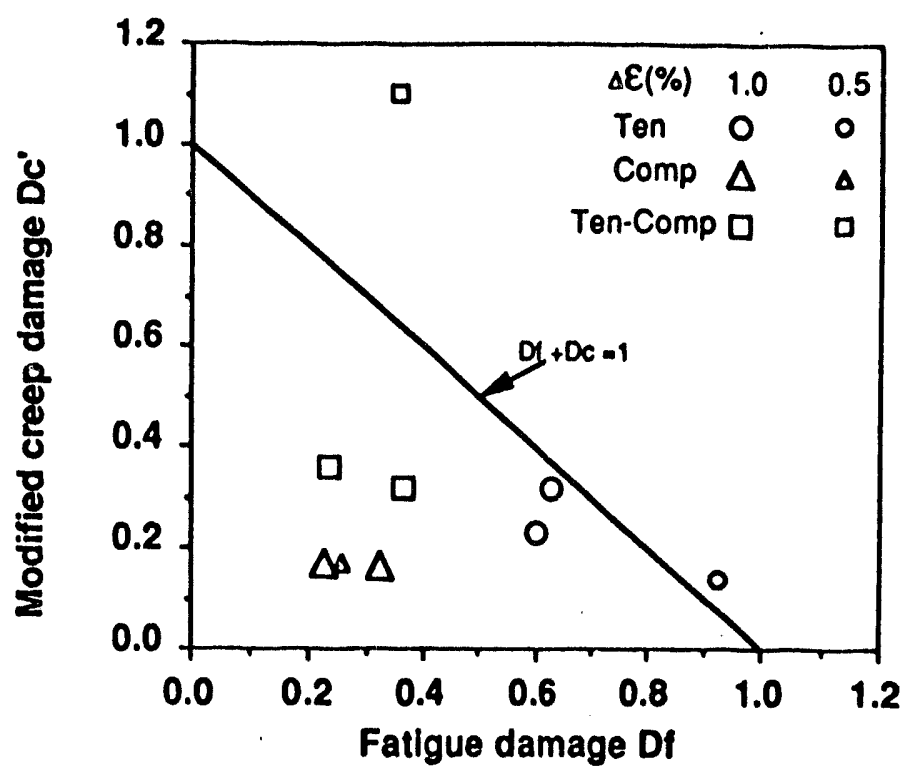

Fig. 8.2. Fatigue and Creep Damage Diagram Based on the Alternative Time Fraction Rule. 
The values of $D$ in all tests increased and those in creep-fatigue tests with tensile hold times approach 1. However the values of $D$ in tests with compressive and tensile-compressive hold times were still lower than 1.

Within the ductility exhaustion method, creep ductility $\varepsilon_{d}$ is defined as true strain at rupture based on reduction in area $R$ :

$$
\begin{gathered}
\varepsilon_{d}=-\log _{0}(1-R) \\
R=1-\frac{A}{A_{0}}
\end{gathered}
$$

where $A_{0}$ and $A$ are initial and final cross-sectional areas of the creep specimen. Creep damage $D_{c d}$ was calculated as follows:

$$
D_{\infty}=N_{1}\left(\int_{0}^{n} \frac{\dot{\varepsilon}_{c}}{\varepsilon_{d}} d t\right)
$$

where $\dot{\varepsilon}_{\mathrm{c}}$ is the absolute value of creep strain rate during the hold period. Because reduction in area remained unchanged for creeprupture times of up to $4,000 \mathrm{~h}, \varepsilon_{d}$ was assumed to be constant for the present material. Then

$$
D_{c d}=N_{1}\left(\frac{\Delta \varepsilon_{c}}{\varepsilon_{d}}\right)
$$

where $\Delta \varepsilon_{c}$ is the absolute value of accumulated creep strain during the hold period. $D_{f}$ is obtained from an equation similar to Eq. (8.1). The $D_{f}-D_{c d}$ diagram for creep-fatigue tests is shown in Fig. 8.3. Also shown in Fig. 8.3 are the R5 criterion [9] (for which $D=1$ ) and the UKAEA criterion [10] (an L-shaped region in the diagram). Although the $D_{c}$ values calculated by this method are larger than those obtained by the time fraction rule, the $D_{c}$ values now depend on strain range (the trend reported for type 304 stainless steel [11]). 


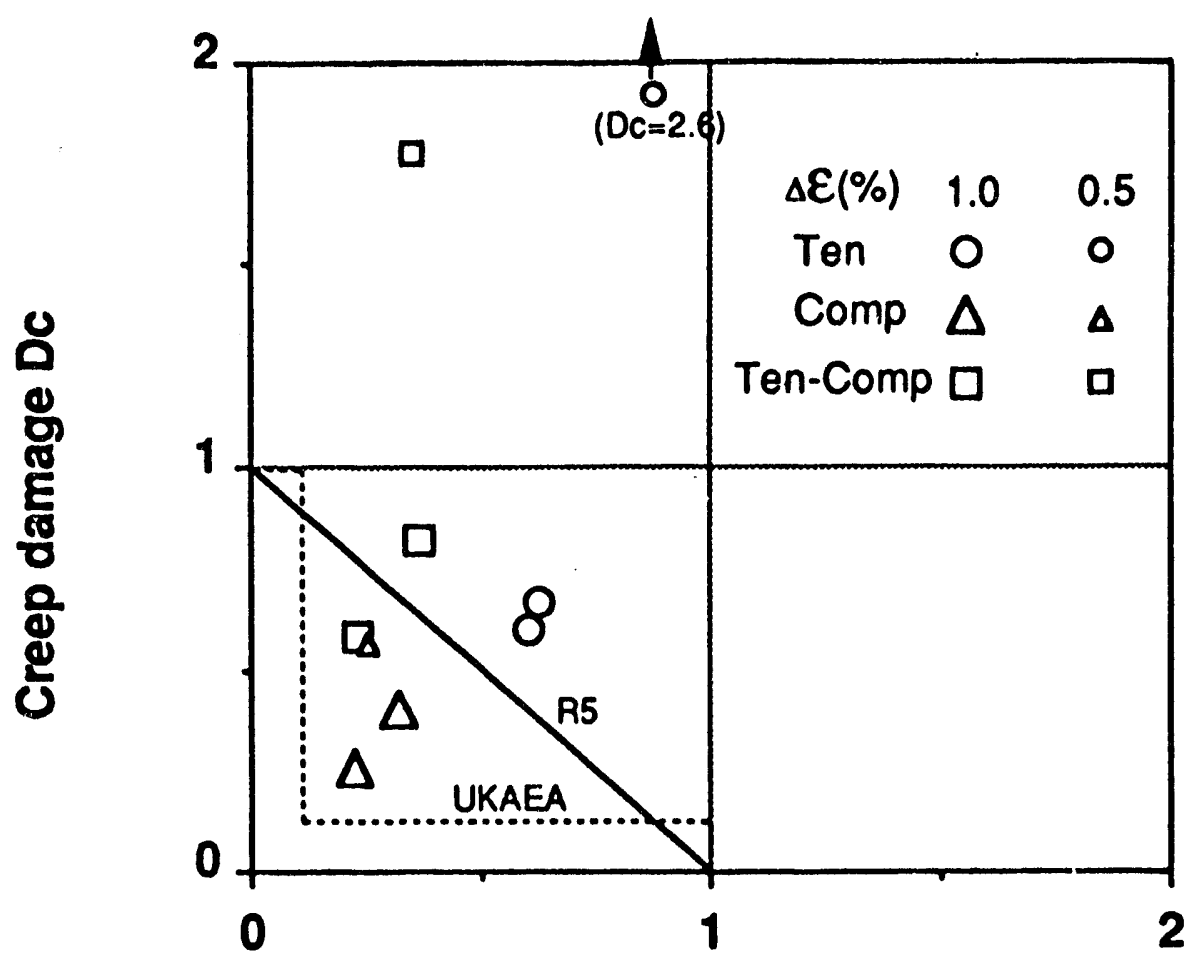

Fatigue damage Df

Fig. 8.3. Fatigue and Creep Damage Diagram Based on the Ductility Exhaustion Method.

This results in larger $D_{c}$ values for lower strain ranges. Conservative estimates of creep-fatigue life for the tests with tensile hold times can be obtained with the R5 procedure. Conversely, the UKAEA criterion should be used to obtain conservative life estimates for tests with compressive and tensile-compressive hold times.

Results discussed above demonstrate that the creep-fatigue life in tests with tensile hold times can be evaluated by both the linear damage rule (with some modifications) and the ductility exhaustion method with $D=1$. However, the creep-fatigue damage criterion $D$ should be modified significantly for life evaluation under compressive hold times. 


\subsection{LIFE EVALUATION WITH A NEW METHOD}

The following observations were made during the creep-fatigue tests.

1. Creep cavity initiation in grain boundaries is insignificant compared to that observed for austenitic stainless steels.

2. Reduction in fatigue life due to compressive hold is greater than that due to tensile hold.

Based on these observations, simplified equations for damage evaluation are proposed:

$$
\begin{gathered}
\frac{d D_{1}}{d N}=A^{-1}\left(1+\left|\alpha D_{c t}-\beta D_{c c}\right|\right) \Delta \varepsilon_{i n}^{-m} \\
\frac{d D_{c t}}{d t}=\frac{\dot{\varepsilon}_{c t}}{\varepsilon_{1}}, \frac{d D_{c c}}{d t}=\frac{\dot{\varepsilon}_{c c}}{\varepsilon_{1}}
\end{gathered}
$$

where $D_{f}$ is fatigue damage, $D_{c t}$ and $D_{c c}$ are tensile and compressive creep damages, respectively, $\Delta \varepsilon_{\text {in }}$ is inelastic strain range, $\dot{\varepsilon}_{\mathrm{ct}}$ and $\dot{\varepsilon}_{\mathrm{cc}}$ are tensile and compressive creep strain rates, respectively, and $\varepsilon_{f}$ is the true creep rupture strain. $A$ and $m$, respectively, are the coefficient and exponent in the fatigue life - inelastic strain range relation for pure cyclic fatigue. Constants $\alpha$ and $\beta$ are creep damage factors for tensile and compressive creep determined from tensile and compressive hold tests, respectively. Fatigue life can be expressed by:

$$
N_{1}=\frac{-1+\left(1+2\left|\alpha D_{c t}-\beta D_{c c}\right| A \Delta \varepsilon_{i n}^{-m}\right)^{1 / 2}}{\left|\alpha D_{c t}-\beta D_{c c}\right|}
$$

For biaxial creep-fatigue life evaluation, Eqs. (8.8) and (8.9) are replaced by the following equations: 


$$
\begin{aligned}
& \frac{d D_{1}}{d N}=A^{-1}\left(1+\left|\alpha D_{c t}-\beta D_{c c}\right|\right) \overline{\Delta \gamma}_{l m}^{-m} \\
& \frac{d D_{c t}}{d t}=\frac{\dot{\varepsilon}_{c t m}}{\varepsilon_{t m}}, \frac{d D_{c c}}{d t}=\frac{\dot{\varepsilon}_{c c m}}{\varepsilon_{t m}} .
\end{aligned}
$$

Here $\Delta \varepsilon_{\text {in }}$ is replaced with the inelastic equivalent shear strain range, $\overline{\Delta \gamma}_{\text {in }}$, which is a function of the inelastic maximum shear strain range, $\Delta \gamma_{\max }$ in, and the normal strain range, $\Delta \varepsilon_{\text {in }}$, on the $\Delta \gamma_{\max }$ plane. Inelastic equivalent shear strain range, $\overline{\Delta \gamma}_{\text {in }}$, is expressed as:

$$
\begin{gathered}
\overline{\Delta \gamma}_{\text {in }}=\frac{\Delta \gamma_{\max \text { in }}}{2}+2.7 \Delta \varepsilon_{\text {in }}, \quad(\text { in-phase }) \\
\overline{\Delta \gamma_{\text {in }}}=\frac{\Delta \gamma_{\max \text { in }}}{2}+1.4 \Delta \varepsilon_{\text {in }}, \quad\left(90^{\circ} \text { out-of-phase }\right) .
\end{gathered}
$$

Equations (8.13) and (8.14) are based on the iso- $N_{f}$ contours on the $\Gamma$ plane obtained from the biaxial fatigue test data presented in Section 7.1 and in Ref. 3.

Creep strain rate and true creep rupture strain uncler biaxial stress conditions in Eq. (8.12) were assumed to be of the von Mises type.

Based on Eqs. (8.13) and (8.14) biaxial creep-fatigue life can be represented by:

$$
N_{1}=\frac{-1+\left(1+2\left|\alpha D_{c t}-\beta D_{c c}\right| A \overline{\Delta \gamma}_{i n}^{-m}\right)^{1 / 2}}{\left|\alpha D_{c t}-\beta D_{c c}\right|}
$$

The creep damage factors $\alpha$ and $\beta$ are determined to be 0.32 and 5.4 based on the uniaxial creep fatigue data reported in the present study and in Ref. 3. The constant A in Eqs. (8.10) and (8.15) is 1.62 and 1.2 , respectively. The constant $m$ is -1.48 in both equations. Equations (8.10) and (8.15) were used to predict creep-fatigue life in uniaxial and biaxial creep-fatigue tests. Predictions are compared to experimental results in Fig. 8.4. 


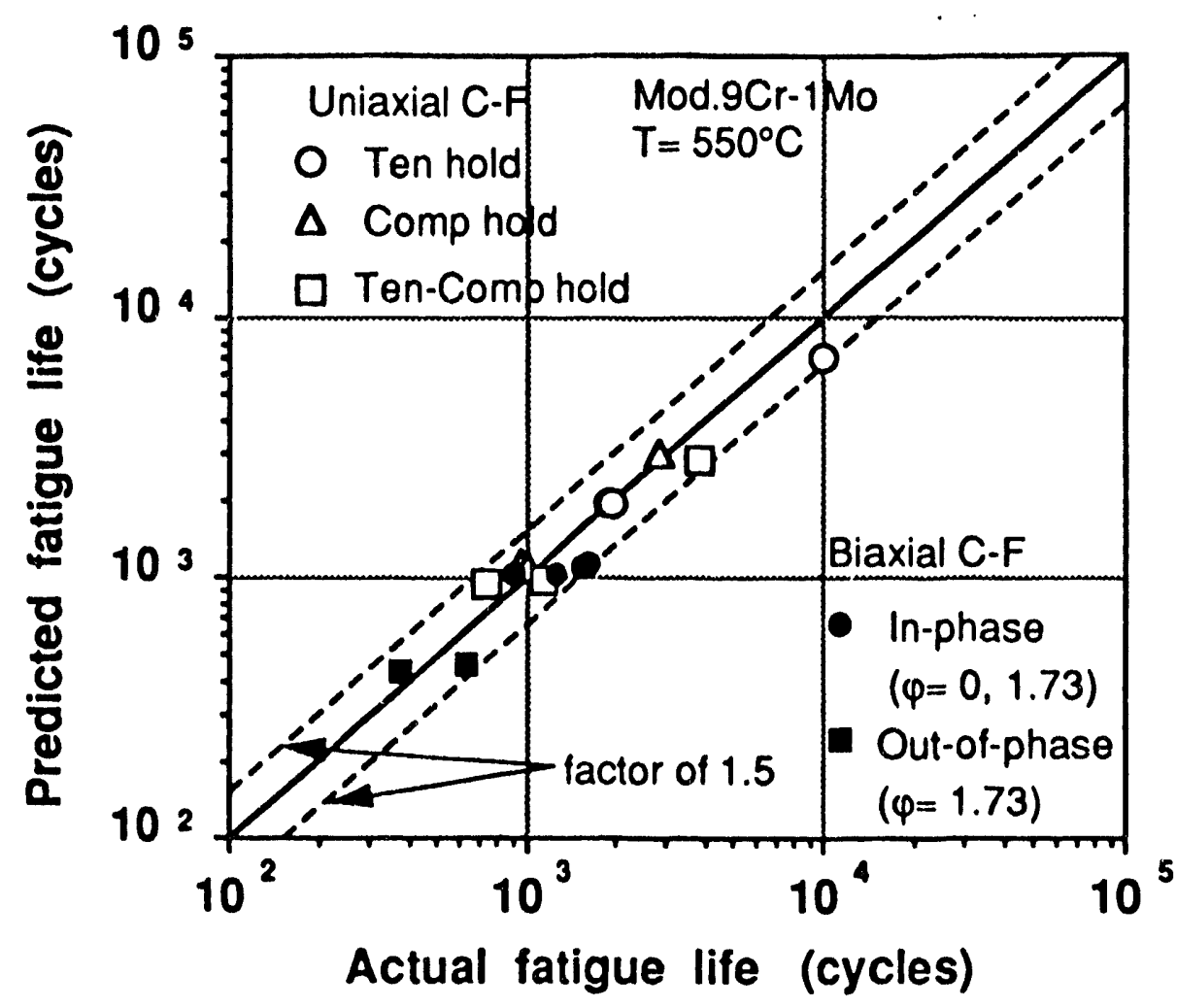

Fig. 8.4. Fatigue Life - Experimental Results and Predictions.

It is seen that the new method yields satisfactory predictions of the creep-fatigue life in both uniaxial and biaxial cases. However, further validation of the proposed method is recommended.

\section{CONCLUDING REMARKS}

A series of fatigue, creep, and creep-fatigue tests under uniaxial and biaxial loading conditions have been performed with the purpose of investigating deformation properties and developing creepfatigue life evaluation methods for modified $9 \mathrm{Cr}-1 \mathrm{Mo}$ steel. The following conclusions were drawn from results obtained at CRIEPI: 
1. Creep behavior appears to be affected by prior cyclic loading. Steady state creep strain rate increases significantly.

2. Tensile hold times of up to $1 \mathrm{hr}$ had no significant effect on fatigue life. No creep cavities were observed in specimens subjected to creep-fatigue loading with tensile hold times. Conversely, fatigue life reduction was observed in specimens subjected to tests with compressive and tensile-compressive hold times.

3. Biaxial low cycle fatigue life can be reasonably well correlated with the equivalent strain range $\overline{\Delta \gamma}$ for both in-phase and $90^{\circ}$ out-of-phase tests. Thus the equivalent strain range $\overline{\Delta \gamma}$ appears to be a suitable parameter for evaluating biaxial fatigue life.

4. In creep-fatigue tests with tensile hold times, the creepfatigue life can be evaluated reasonably well by both the linear damage rule (with minor modifications) and by the ductility exhaustion method. However, in the case of tests with compressive hold times, the creep-fatigue damage criterion D requires significant modifications.

5. A new method for evaluating uniaxial and biaxial creep-fatigue life of modified $9 \mathrm{Cr}-1 \mathrm{Mo}$ steel was proposed. The new method produces predictions within the factor of 1.5 on life regardless of the position of the hold period within the creep-fatigue cycle. Recommendations for future work include further validation of the method.

\section{ACKNOWLEDGEMENT}

The authors gratefully acknowledge useful technical discussions with J. J. Blass and G. T. Yahr of Oak Ridge National Laboratory, and thank Dr. Blass and Mr. Yahr for reviewing the manuscript. 


\section{REFERENCES}

1. M. B. Ruggles, S. Cheng, and E. Krempl, "The Rate (Time)Dependent Mechanical Behavior of Modified $9 \mathrm{Cr}-1 \mathrm{Mo}$ Steel. Experiments at $538^{\circ} \mathrm{C}$, Transactions of the 11th International Conference on Structural Mechanics in Reactor Technology, 1823 August, 1991, Tokyo, Vo. L, pp. 145-150.

2. J. C. Moosbrugger, "Development and Confirmation of Improved Inelastic Deformation Model" in JAPC-USDOE Joint Study on Structural Design Methods and Data for Modified 9Cr-1Mo Steel. Annual Report for the Period April 1, 1990-March 31, 1991, ORNL/9CR/91-1, March 1991, pp. 75-103.

3. K. Aoto, T. Koakutsu, Y. Wada, and M. Hrano, "The Prediction of The Stress Relaxation Behavicr of The High-Temperature Structural Materials by Creep-Strain Equations.", Transactions of the International Conference on Creep, 450-495, (1986).

4. H. Kawasaki, K. Aoto, and Y. Wada, "Analytical Representation of Creep Properties of Mod.9Cr-1Mo Steel", Transactions of the 11 th International Conference on Structural Mechanics in Reactor Technology, Vol. L, 343-348, (1991).

5. M. Matubara and T. Ogata, "Creep-Fatigue Strength Evaluation of Modified 9Cr-1Mo Steel for FBR Steam Generator", (in Japanese), Denryokuchuou Kenkyuusho Houkoku T91011, (1991).

6. T. Ogata, A. Nitta, and K. Kuwabara, "Biaxial Low-Cycle Fatigue Failure of Type 304 Stainless Steel Under In-Phase and Out-ofPhase Straining Condition", Fatigue Under Biaxial and Multiaxial Loading, K. F. Kussmaul, Ed., MEP ESIS10, 377-392, (1991).

7. A. Nitta, T. Ogata, and K. Kuwabara, "Fracture Mechanisms and Life Assessment Under High-Strain Biaxial Cyclic Loading of Type 304 Stainless Steel.", Fatigue and Fracture of Engineering Materials and Structures, Vol. 12, No. 2, 77-92, (1989).

8. Fatigue Damage Evaluation Method of Modified 9Cr-1Mo Steel", in Japanese, Proceedings of the 29th Symposium on Strength of Materials at High Temperature, 136-139, (1991). 
9. R5, An Assessment Procedure for the High Temperature Response of Structures, Berkeley Nuclear Laboratories, Nuclear Electric plc, (1990).

10. A. M. Clayton, "Creep-Fatigue Assessment Procedures for Fast Reactors", Recent Advances in Design Procedures for High Temperature Plant, IMechE MEP, 49-54, (1988).

11. Y. Takahashi, T. Ogata, and K. Take, "Study on Creep-Fatigue Prediction Methods for Type 304 Stainless Steel", Proceedings of the 8th International Seminar on Inelastic Analysis, Fracture and Life Prediction, 71-89, (1991). 
ORNL/M-3198

\section{INTERNAL DISTRIBUTION}

1. R. L. Battiste

2. J. J. Blass

3. R. S. Booth

4. C. R. Brinkman

5. S. H. Buechler

6. S-J. Chang

7. J. A. Clinard

8. J. M. Corum

9. R. C. Gwaltney

10. R. G. Gilliland

11. W. R. Hendrich

12. F. J. Homan

13. R. L. Huddleston
14. J. E. Jones Jr.

15. J. G. Merkle

16. C. E. Pugh

17. C. R. Richmond

18. P. L. Rittenhouse

19-28. M. B. Ruggles

29. G. T. Yahr

30. ORNL Patent Section

31. Central Research Library

32. Document Reference Section

33-34. Laboratory Records Department

35. Laboratory Records, RC

\section{EXTERNAL DISTRIBUTION}

36. Office of Assistant Manager for Energy Research and Development, U. S. Department of Energy, OR, P. O. Box 2008, Oak Ridge, TN 37831-6269

37-46. Office of Scientific and Technical Information, $U$. S. Department of Energy, P. O. Box 62, Oak Ridge, TN 37831

47. M. Gabler, Rocketdyne Division, Rockwell International, 6633 Canoga Avenue, Canoga Park, CA 91303

48. E. L. Gluekler, General Electric Company, Advanced Nuclear Technology, 6835 Via Del Oro, Box 530954, San Jose, CA 95153-5354

49. K. R. Jaquay, Rocketdyne Division, Rockwell International, 6633 Canoga Avenue, Canoga Park, CA 91303

50. R. I. Jetter, Rocketdyne Division, Rockwell International, 6633 Canoga Avenue, Canoga Park, CA 91303

51-80. E. Rodwell, Electric Power Research Institute, 3412 Hillview Avenue, P. O. Box 10412, Palo Alto, CA 94303 
81. D. K. Rhyne, Jr., Energy Programs Division, U. S. Department of Energy, OR, P. O. Box 2001, Oak Ridge, TN 37831-6269

82. L. K. Severud, Westinghouse-Hanford Company, P. O. Box 1970, MS-H5-60, Richland, WA 99352 


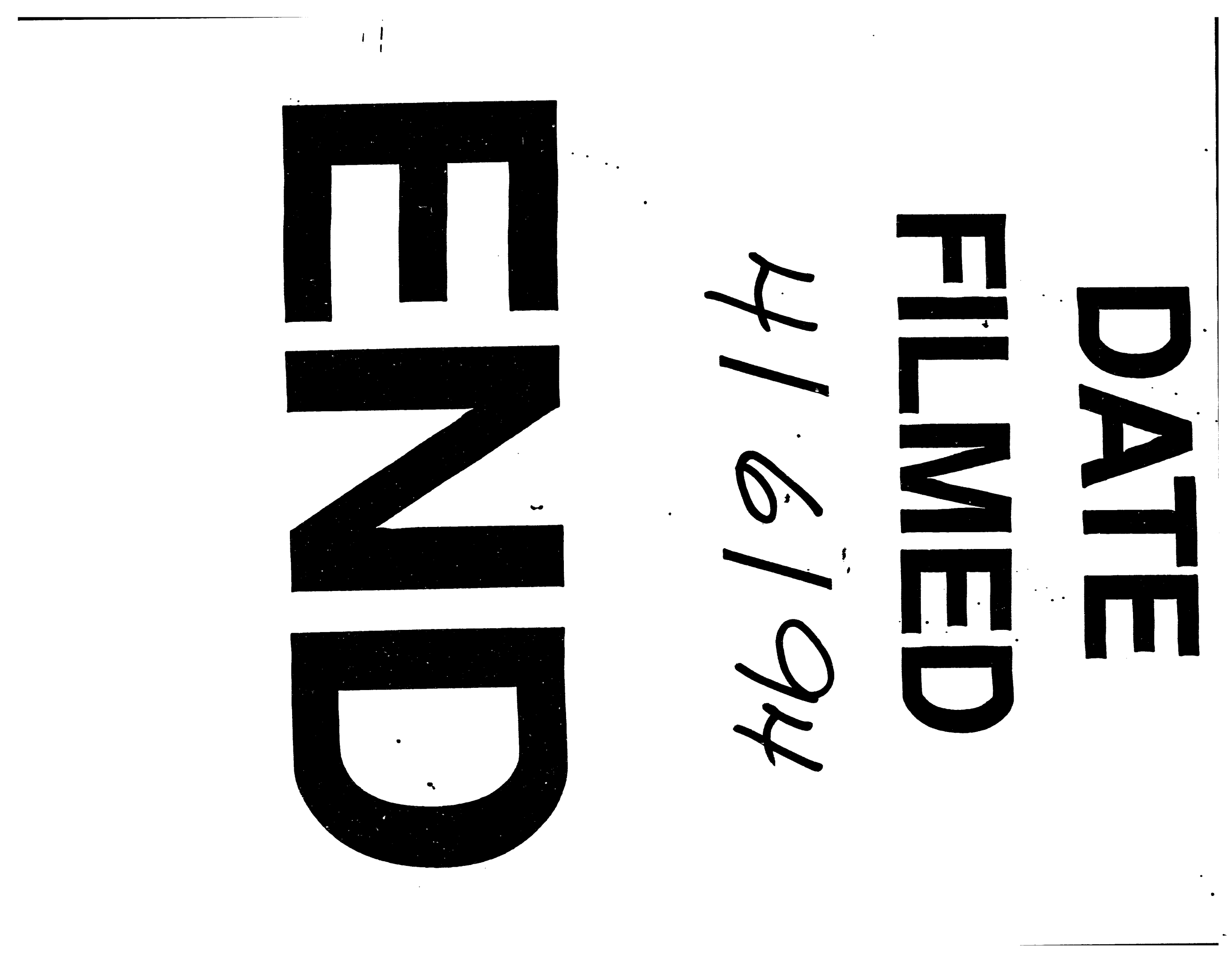


